\title{
Government Spending Multipliers Under the Zero Lower Bound: Evidence from Japan
}

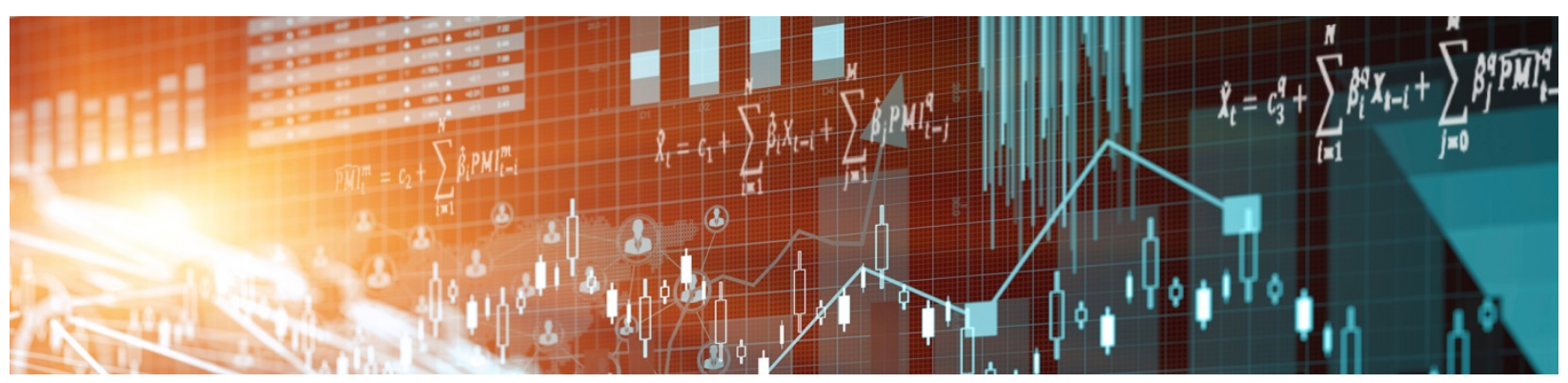

by Wataru Miyamoto, Thuy Lan Nguyen and Dmitriy Sergeyev 
Bank of Canada Staff Working Paper 2017-40

September 2017

\title{
Government Spending Multipliers Under the Zero Lower Bound: Evidence from Japan
}

\author{
by \\ Wataru Miyamoto, ${ }^{1}$ Thuy Lan Nguyen $^{2}$ and Dmitriy Sergeyev ${ }^{3}$ \\ ${ }^{1}$ Canadian Economic Analysis Department \\ Bank of Canada \\ Ottawa, Ontario, Canada K1A 0 G9 \\ wmiyamoto@bankofcanada.ca \\ 2 Santa Clara University \\ tlnguyen@scu.edu \\ ${ }^{3}$ Bocconi University \\ dmytro.sergeyev@unibocconi.it
}




\section{Acknowledgements}

We thank Francesco Giavazzi, Yuriy Gorodnichenko, Takeo Hoshi, Nir Jaimovich, Oscar Jorda, Andrew Levin, Emi Nakamura, Vincenzo Quadrini, Valerie Ramey, Etsuro Shioji, Jón Steinsson, Tsutomu Watanabe, Johannes Wieland, Sarah Zubairy and seminar and conference participants at the AEA 2016 meetings, 2015 Econometric Society European Winter Meeting, SED 2016, Stanford Juku 2016, 2017 NBER Japan Project Meeting, the Bank of France, Brown University, Bocconi University, Higher School of Economics, New Economic School, USC Marshall, UC Davis, UNC Chapel Hill, University of Washington Seattle, University of British Columbia, Simon Fraser University, the Japanese Ministry of Finance, and Columbia Japan Economic Seminar for their feedback and discussions. Akihisa Kato provided excellent research assistance. We are grateful to the Japan Center for Economic Research for kindly providing the forecast data we used in this paper. 


\begin{abstract}
Using a rich data set on government spending forecasts in Japan, we provide new evidence on the effects of unexpected changes in government spending when the nominal interest rate is near the zero lower bound (ZLB). The on-impact output multiplier is 1.5 in the ZLB period, and 0.6 outside of it. We estimate that government spending shocks increase both private consumption and investment during the ZLB period but crowd them out in the normal period. There is evidence that expected inflation increases by more in the ZLB period than in the normal period.
\end{abstract}

Bank topics: Fiscal policy; Economic models

JEL codes: E32; E62; E5

\title{
Résumé
}

À l'aide de données détaillées sur les prévisions de dépenses publiques au Japon, nous présentons des éléments nouveaux sur les effets des variations non anticipées des dépenses publiques lorsque le taux d'intérêt nominal avoisine la valeur plancher. Lorsque les taux sont à zéro, le multiplicateur de la production à l'impact est de 1,5 alors qu'il est de 0,6 lorsque les taux n'avoisinent pas la valeur plancher. Nous estimons que les chocs touchant les dépenses publiques font augmenter la consommation et l'investissement privés quand les taux sont à la valeur plancher, mais qu'ils ont en temps normal un effet d'éviction sur ces deux variables. Nos données montrent que quand les taux sont à la valeur plancher, l'inflation anticipée progresse plus fortement qu'en temps normal.

Sujets : Politique budgétaire; Modèles économiques

Codes JEL : E32; E62; E5 


\section{Non-Technical Summary}

\section{Motivation and Question}

The global financial crisis of 2007-08, which forced the central banks in many developed countries to keep their short-term nominal interest rates close to the zero lower bound (ZLB), brought fiscal policy to the center of policy debates. One of the fiscal issues that has received considerable attention in the literature is the government spending multiplier, which is defined as the percentage change in GDP in response to a change in government spending equal to 1 percent of GDP. Some theoretical papers in this literature argue that in a standard New Keynesian model, the government spending multiplier at the ZLB can be much larger than that outside of the ZLB (normal times), which means that government spending can be a powerful tool to stimulate the economy at the ZLB. Nevertheless, there is not much empirical evidence for this theoretical prediction. Motivated by this observation, in this paper, we address two questions: Is there evidence that the government spending multiplier at the ZLB is larger than that in the normal period? Is the New Keynesian mechanism consistent with this evidence?

\section{Methodology}

We use Japanese data from 1980Q1 to 2014Q1 in order to estimate the effects of government spending shocks on the aggregate economy when the nominal interest rate is at the ZLB and outside of the ZLB period. A number of factors make the Japanese ZLB experience the best case to study the effects of government spending in the ZLB period. First, Japan experiences the longest ZLB episode. The nominal interest rate in Japan has been near zero since 1995Q4. Second, during this period, Japan has gone through four business cycles, so we can distinguish between evidence coming from the ZLB period and evidence coming from periods of recession. Third, we can exploit a rich data set that includes not only standard macroeconomic variables but also forecasts of government spending and other variables such as inflation and expected inflation to investigate the propagation mechanism of government spending shocks. In our sample, the normal period is between 1980Q1 and 1995Q3, and the ZLB period in Japan spans between 1995Q4 and 2014Q1.

\section{Key Contributions}

We provide new evidence on the effects of unexpected changes in government spending when the nominal interest rate is at the ZLB. We then examine how our empirical findings are consistent with several hypotheses including the New Keynesian mechanism.

\section{Findings}

We find that the on-impact output multiplier is 1.5 in the ZLB period, while it is 0.6 outside the ZLB. Government spending crowds private consumption and investment during the ZLB period, but it crowds them out in the normal period. We find that some of the empirical findings are consistent with the New Keynesian mechanism.

\section{Future Research}

Although our analysis suggests that a simple New Keynesian model may reproduce some of our empirical evidence, a considerable amount of work remains to test the predictions of different theoretical models. One direction is to examine the effects of other types of shocks at the ZLB such as technology and tax shocks, which can also have different effects during the ZLB period compared with those during the normal period. 


\section{Introduction}

How large is the output multiplier, defined as the percentage increase in output in response to an increase in government spending by 1 percent of GDP, during periods when nominal interest rates are at the zero lower bound (ZLB)? The global financial crisis of 2007-08, which forced the central banks in many developed countries to keep their short-term nominal interest rates close to the ZLB, brought this question to the center of policy debates. ${ }^{1}$

The theoretical literature provides a wide range of answers. In a simple real business cycle model such as Baxter and King (1993), the output multiplier is below one and independent of the ZLB. In New Keynesian models, the output multiplier in the ZLB period ranges from a negative to a large positive number. For example, Woodford (2011), Eggertsson (2011), and Christiano, Eichenbaum, and Rebelo (2011) show that the multiplier can be substantially larger than one in a standard New Keynesian model in which the ZLB period is caused by a fundamental shock. In this environment, temporary government spending is inflationary, which stimulates private consumption and investment by decreasing the real interest rate. As a result, the output multiplier can be well above three, which is much larger than the prediction of this model under active monetary policy. At the same time, Mertens and Ravn (2014) argue that the output multiplier during the ZLB period is quite small in a New Keynesian model in which the period is caused by a non-fundamental confidence shock. In this situation, government spending shocks are deflationary, which increases real interest rates and reduces private consumption and investment. As a result, the output multiplier during the ZLB period is lower than one-it can even be negative-and it is lower than it is outside of the ZLB period.

Empirical estimation of the multiplier when the nominal interest rate is at the ZLB is challenging. First, in most countries, ZLB periods are rare and not extremely persistent. Coibion et al. (2016) calculate that in the post-World War II period up to 2015Q4, the average frequency of the ZLB experiences in advanced countries is 0.075 ( 0.058 without Japan), and the average duration of the ZLB periods is 3.6 years (2.9 years without Japan). Although the ZLB duration of 7.5 years in the United States after the start of the Great Recession is longer than average, it is not sufficiently long to produce a precise estimate of the multiplier. Second, the ZLB periods often coincide with large recessions, making it difficult to separate evidence of the ZLB period from that of the recession. Third, even though there were some ZLB episodes in the early

\footnotetext{
${ }^{1}$ As of this writing, a number of countries, including Denmark, Sweden, and Switzerland, have reduced their short-term nominal interest rates to less than zero, raising the question of whether the zero bound is a constraint on monetary policy. Thus, the term "zero interest rate policy" might seem more appropriate than "zero lower bound." In this paper, we will use the term "zero lower bound" in the sense of "zero interest rate policy." See Rognlie (2015) for a theoretical analysis of monetary policy with negative interest rates.
} 
twentieth century, several of those periods coincided with World War II, when rationing was in place, thus confounding the multiplier estimation.

Using Japanese data from 1980Q1 to 2014Q1, we present new estimates of the effects of government spending shocks on the aggregate economy when the nominal interest rate is at the ZLB (i.e., in the ZLB period) and outside of the ZLB period (i.e., in the normal period). We exploit a rich data set that includes not only standard macroeconomic variables but also forecasts of government spending and other variables such as inflation and expected inflation to investigate the propagation mechanism of government spending shocks.

A number of factors make the Japanese ZLB experience the best case to study the effects of government spending in the ZLB period. First, Japan is experiencing the longest ZLB episode. The nominal interest rate in Japan has been near zero since 1995Q4. Second, during this period, Japan has gone through four business cycles, so we can distinguish between evidence coming from the ZLB period and evidence coming from periods of temporary recession. Third, Japan has no rationing in effect during the ZLB period.

Our identification strategy is as follows: First, to identify exogenous changes in government spending, we assume that government spending does not react to output changes within the same quarter. This assumption, proposed by Blanchard and Perotti (2002), relies on the idea that governments need time to decide on and implement changes in government spending. ${ }^{2}$ Second, we control for expected changes in government spending using quarterly forecasts of future government spending produced by the Japanese Center for Economic Research (JCER), as well as predicted changes in government spending based on past macroeconomic variables. The motivation for including expectations is that people may change their behavior in anticipation of future government spending changes, which can bias the estimated multiplier without removing expected government spending changes. In fact, we find that omitting forecast data when identifying government spending shocks changes the estimated multiplier in a non-trivial way, implying that it is important to control for expectations.

Using the Jorda (2005) local projection method, we find that the output multiplier is 1.5 on impact in the ZLB period and 0.6 in the normal period. At longer horizons, the output multiplier increases to greater than two in the ZLB period and becomes negative in the normal period. The differences between the output multipliers in the ZLB and normal periods are statistically significant at the 5 percent level. These results are

\footnotetext{
${ }^{2}$ This assumption was criticized in the case of the United States (Barro and Redlick, 2011; Ramey, 2011b). Non-defense spending can contemporaneously be affected by changes in aggregate output because a large part of state and local spending in the United States automatically responds to cyclical variations in state and local revenues. The identification assumption may be less problematic in Japan. Prefecture and local spending is not restricted by contemporaneous prefecture and local revenues because the central government can finance a large part of local spending and the local government can issue debt. The central government can also issue debt to finance their spending, especially for public investment, which is a volatile component of total government spending.
} 
robust to adding more controls to our estimation. For example, we use forecasts of future output to control for the possibility that current government spending and output may react to expected future changes in output. We also add forecasts from the IMF, the OECD, and the Japanese Cabinet Office's Economic Outlook and Basic Stance for Economic and Fiscal Management.

We estimate that government spending shocks crowd out private consumption and investment in the normal period, but crowd them in during the ZLB period. This difference is statistically significant at the 1 percent level at most horizons. The unemployment rate exhibits a large, significantly negative response in the ZLB period, but only a marginal drop in the normal period.

We examine empirically whether the New Keynesian inflation expectation channel can explain the higher multiplier in the ZLB period. To that end, we compute the responses of inflation, expected inflation, and the nominal interest rate to a positive government spending shock. While the responses of inflation measured by the GDP deflator are only slightly larger in the ZLB period than in the normal periods, CPI inflation responds more positively and significantly in the ZLB period than in the normal period. Expected inflation measured by the four-quarters-ahead forecast of inflation increases more in the ZLB period than in the normal period. The short-term nominal interest rate in the normal period increases, while it stays around zero in the ZLB period. This result implies that the short-term real interest rate does not increase as much in the ZLB period as in the normal period in response to government spending shocks.

We argue that the difference between our estimated output multiplier in the ZLB period and that in the normal period is unlikely to be driven by the effects of government spending in temporary recessions. We exploit the fact that Japan experienced several business cycles during the ZLB period. The Japanese economy was in recession half of the time during the normal period but only a third of the time during the ZLB period. Therefore, the multiplier during the ZLB period would be smaller than the multiplier during the normal period if the only fundamental difference was that the multipliers were larger in recessions. However, we find a larger multiplier in the ZLB period than in the normal period.

We cannot rule out that a permanently elevated level of slack that coincides with the ZLB period may explain the larger output multiplier in the ZLB period in Japan. However, there are two reasons to believe that the ZLB can be an important factor in accounting for our results. First, some of our empirical findings are consistent with the predictions of a New Keynesian model: there is evidence that inflation expectations respond more strongly during the ZLB period than in the normal period. In addition, consumption and investment are crowded in during the ZLB period after a positive government spending shock, while they are crowded out in the normal period. Second, recent theoretical models that generate slack-dependent multipliers, such as Michaillat (2014) and Michaillat and Saez (2017), predict that the relevant measure of 
slack is labor market tightness rather than unemployment. However, labor market tightness did not increase permanently around the start of the ZLB period in Japan.

Furthermore, we argue that the identification assumption that we use (i.e., that government spending does not respond to output changes within a quarter) does not explain the difference between the multipliers in the ZLB and normal periods. In particular, the estimates of the multipliers are biased if there is a non-zero elasticity of a contemporaneous government spending reaction to output. However, if the elasticity of this reaction is the same in both the ZLB and normal periods, the bias will be approximately the same across the two periods, and our estimate of the difference in multipliers would remain roughly unchanged. To explain the difference in the multipliers in the ZLB period and the normal period, the elasticity of a government spending reaction to changes in current output has to be substantially different in the two periods.

Related Literature. Our paper contributes to a large body of work in macroeconomics that estimates the effects of government spending changes on the economy. For example, Blanchard and Perotti (2002), Ramey (2011b), Barro and Redlick (2011), Fisher and Peters (2010) and many other papers identify the output multipliers for the United States using different identification schemes, such as the institutional information approach in a structural vector autoregression (SVAR), military spending, war dates, and stock returns. Ramey (2011a) provides a comprehensive survey. The papers in this literature often find the output multiplier to be smaller than one. We also estimate the output multiplier to be smaller than one in the normal period in Japan. ${ }^{3}$

Recent literature estimates state-dependent output multipliers. For example, Auerbach and Gorodnichenko (2012a,b, 2014) estimate output multipliers during recessions and expansions using U.S., OECD, and Japanese data. Our paper focuses instead on comparing the multipliers in the ZLB and normal periods. We argue that the difference is not due to the non-linear effects of government spending during temporary expansion and recession. We also exploit more data on Japan: for example, we include quarterly forecast data of government spending to control for expectations throughout our sample between 1980Q1 and 2014Q1. We also adjust the published government spending data to exclude transfers.

Few papers estimate the output multiplier in the ZLB periods. Ramey (2011b) does not find evidence that the output multiplier is higher in the period when the short-term nominal interest rate was near zero (between 1939 and 1951) in the United States. Crafts and Mills (2012) estimate that the multiplier is below one in the United Kingdom during the 1922-38 period when the nominal interest rate is near zero. We present the evidence from a more recent and longer ZLB period in Japan.

\footnotetext{
${ }^{3}$ Watanabe, Yabu, and Ito (2010) estimated the output multiplier in Japan between 1965 and 2004. Their estimates range between 0.69 and 0.95 , depending on specifications.
} 
The closest work to our paper is Ramey and Zubairy (2016), who examine U.S. data from 1889, which include two ZLB periods, 1932Q2-1951Q1 and 2008Q4-2013Q4. During World War II, the U.S. government rationed many goods such as food, gas, tires and clothing. Therefore, estimation using data from this period can confound the effects of government spending in the ZLB period and those in rationing states. Indeed, when Ramey and Zubairy (2016) exclude World War II-era data from their sample, the multiplier in the ZLB period is larger than when they include that data, and it is larger than the multiplier during the normal period. Unlike Ramey and Zubairy (2016), we present new evidence using Japanese data with a long spell of the ZLB occurring in recent times. There were no wars or rationing in the economy in the time period we consider. Furthermore, we avoid the gold standard and the fixed nominal exchange rate periods, which can affect the size of the multipliers. We examine not only output but also other aggregate variables to shed light on the mechanism driving the results.

Some recent papers use regional panel data and various "natural experiments" to estimate the regional multipliers by keeping national monetary policy fixed. For example, Nakamura and Steinsson (2014) estimate the regional output multiplier for states within the United States, and Bruckner and Tuladhar (2014) do the same for Japanese prefectures. ${ }^{4}$ However, Nakamura and Steinsson (2014), Farhi and Werning (2012), and Ramey (2011a) note that the regional multiplier is not the same as the aggregate multiplier in the ZLB period. For example, in a typical open-economy New Keynesian model, the long-term real interest rate does not fall in regions with a common monetary policy. However, the long-term real interest rate falls in the ZLB period in a typical closed-economy New Keynesian model. As a result, one needs a model to map the regional multiplier to the aggregate multiplier. In contrast to these papers, we directly estimate the aggregate multiplier in the ZLB period.

The paper is also related to the literature that tests various ZLB predictions of New Keynesian models. For example, Wieland (2013) examines whether negative aggregate supply shocks, proxied by oil price changes and the Great East Japan Earthquake, are expansionary during the ZLB periods and finds no convincing evidence of that. Dupor and Li (2015) compare the predictions of a New Keynesian model to empirical impulse responses to a government spending shock during the passive monetary policy period in the United States. Aruoba, Cuba-Borda, and Schorfheide (2016) estimate a New Keynesian model using Japanese data and conclude that the ZLB period in Japan is more likely to be due to a self-fulfilling confidence shock. Unlike these papers, we focus on the effects of government spending shocks in the ZLB period and find that some, but not all, of our empirical findings are consistent with the New Keynesian model.

\footnotetext{
${ }^{4}$ Chodorow-Reich et al. (2012), Shoag (2010), Cohen, Coval, and Malloy (2011) investigate employment effects of local government spending.
} 
The rest of the paper proceeds as follows: Section 2 explains the identification strategy. In Section 3, we describe the data. Section 4 presents the estimates of the output multipliers in the normal and ZLB periods. We show the multipliers for other variables in Section 5. Section 6 discusses potential explanations of our results. Section 7 concludes.

\section{Measurement of Multipliers}

Changes in government spending affect aggregate output, and changes in aggregate output can contemporaneously affect government spending. To extract exogenous variations in government spending unrelated to contemporaneous changes in aggregate output, we assume that government spending does not respond to changes in output within a quarter. This assumption relies on the idea that policy-makers need time to decide on, approve, and implement changes in fiscal policy. Blanchard and Perotti (2002) and subsequent studies by Auerbach and Gorodnichenko (2012a,b), Ilzetzki, Mendoza, and Végh (2013), and others have used this identification assumption.

Another way to identify government spending changes unrelated to aggregate output is to consider large military-spending buildups (Barro, 1981; Barro and Redlick, 2011; Ramey and Zubairy, 2016). However, Japanese military spending accounts for only 1 percent of GDP, and it varies little over time, potentially leading to large sampling errors. At the same time, non-military spending in Japan represents a sizable portion of GDP, and it is more volatile than in the United States.

We remove the anticipated component of government spending changes using a measure of the expectations of future government spending to compute unexpected exogenous changes in government spending. As emphasized by previous literature such as Ramey (2011a) and Alesina, Favero, and Giavazzi (2015), controlling for expected changes in government spending is important because forward-looking agents can respond to news about future government spending before it materializes. The estimation without controlling for expected changes in government spending does not capture all of the effects of government spending and biases the results. Since past macroeconomic variables such as aggregate output, government spending and tax revenues may not be sufficient to fully capture expected changes in government spending, it may be important to include government spending forecast data to control for the predicted government spending variation.

We implement the above strategy to measure the effects of government spending shocks using the local projection method (Jorda, 2005), which estimates impulse response functions by directly projecting a variable of interest on shocks as well as lags of variables usually entering a vector autoregression (VAR). This 
method has some advantages over a VAR analysis. One advantage of the local projection method is that it does not impose linear restrictions on the dynamic patterns of responses. Additionally, it does not require the same variables to be used in each equation, which is useful in computing fiscal multipliers. At the same time, when a VAR correctly captures the data-generating process, it produces more efficient estimates. The local projection method has been used in the literature such as Stock and Watson (2007), Auerbach and Gorodnichenko (2012a,b), and Ramey and Zubairy (2016), among others.

To compute the impulse responses of various variables, we use the following two-step estimation procedure. First, we identify the unexpected innovations in government spending by estimating the following specification:

$$
\Delta \ln G_{t}=\alpha+\gamma F_{t-1} \Delta \ln G_{t}+\psi(L) y_{t-1}+\varepsilon_{t},
$$

where $\Delta \ln G_{t}$ is the $\log$ difference of government spending, $F_{t-1} \Delta \ln G_{t}$ is the one-period-ahead forecast of $\Delta \ln G_{t}, y_{t-1}$ is a vector of controls, and $\psi(L)$ is a lag operator. All variables are in real per-capita terms. The estimated residuals, $\widehat{\varepsilon}_{t}$, are the unexpected government spending changes orthogonal to the expected component of government spending and information in the control variables, so $\widehat{\varepsilon}_{t}$ is our government spending shocks. If forecast $F_{t-1} \Delta \ln G_{t}$ incorporates all of the information available to agents, there is no need to add controls $\psi(L) y_{t-1}$ as additional regressors in equation (1). However, to account for the possibility that households' information set may be different from that of forecasters due to the timing of our forecast data as we discuss below, we include a vector of controls in the estimation. ${ }^{5}$ Additionally, we note that forecast data for government spending do not correspond exactly to our "adjusted" government spending as explained in Section 3, so we include forecast data on the right-hand side in the estimation instead of using forecast errors or assuming $\gamma=1$. In what follows, we define "the standard controls" to be the growth rate of government spending, the growth rate of tax revenue, the growth rate of output, and the unemployment rate. We include the unemployment rate in the standard controls following Barro (1981) and Barro and Redlick (2011), who find that the unemployment rate contains important information about the state of the business cycle relative to output data. We add four lags of the control variables in the regressions.

In the second step, we estimate a series of regressions at each horizon $h$ :

$$
x_{t+h}=\alpha_{h}^{x}+\beta_{h}^{x} \cdot \operatorname{shock}_{t}+\psi_{h}^{x}(L) y_{t-1}+\varepsilon_{t+h}^{x}, \quad \text { for } h=0,1,2, \ldots,
$$

where $x_{t}$ is a variable of interest; shock ${ }_{t}$ is the series of government spending shocks, proxied by the estimated $\widehat{\varepsilon}_{t}$ in equation (1); and $\psi_{h}^{x}(L)$ is a lag operator. Then, $\beta_{h}^{x}$ is the response of $x$ at horizon $h$ to an

\footnotetext{
${ }^{5}$ We exclude the controls in one of the robustness exercises, and the baseline results do not change.
} 
unexpected government spending shock. When we estimate equation (2) for output, $\psi_{h}^{x}(L) y_{t-1}$ are lags of the standard controls. For all other variables of interest, $\psi_{h}^{x}(L) y_{t-1}$ are lags of the standard controls as well as lags of the variable of interest. We specify separately when we include additional controls. ${ }^{6}$ Note that regression (2) uses the generated regressor shock ${ }_{t}$. In Appendix A, we show that correcting for the generated regressors problem does not change our results significantly. In a related environment, Coibion and Gorodnichenko (2012) also demonstrated that correcting for the generated regressors problem has no significant effect on their results.

To compute multipliers, we estimate the following regression for each horizon $h$ :

$$
\sum_{j=0}^{h} x_{t+j}=\alpha_{h}^{x}+M_{h}^{x} \sum_{j=0}^{h} \frac{G_{t+j}-G_{t-1}}{Y_{t-1}}+\psi_{h}^{x}(L) y_{t-1}+\varepsilon_{t+h}^{x}
$$

where we instrument $\sum_{j=0}^{h} \frac{G_{t+j}-G_{t-1}}{Y_{t-1}}$ with $\widehat{\varepsilon}_{t}$ obtained in (1). In equation (3), $\sum_{j=0}^{h} x_{t+j}$ is the sum of the variable $x$ from $t$ to $t+h$, and $\sum_{j=0}^{h} \frac{G_{t+j}-G_{t-1}}{Y_{t-1}}$ is the sum of government spending from $t$ to $t+h$ normalized by output. $M_{h}^{x}$ is the cumulative multiplier, and its standard errors are calculated using the standard IV estimation formulas. We use heteroskedasticity and autocorrelation consistent (HAC) standard errors that are robust to both arbitrary heteroskedasticity and autocorrelation. We choose automatic bandwidth selection in the estimation.

In case of the output multiplier, the variable of interest $x$ in (3) is $\frac{Y_{t+h}-Y_{t-1}}{Y_{t-1}} \approx \ln Y_{t+h}-\ln Y_{t-1}$. Because cumulative government spending on the right-hand side of (3) is normalized by output, the output multiplier is the cumulative change in output relative to the cumulative change in government spending during $h$ quarters. This definition is similar to that in Mountford and Uhlig (2009) and Ramey and Zubairy (2016).

\section{Data}

We use Japanese quarterly data for the period between 1980Q1 and 2014Q1 in the baseline estimation. There are several benefits of using Japanese data over other countries, including the United States, to examine the effects of government spending on the economy in the ZLB period. First, Japan has more information about its ZLB period than other countries. As plotted in Figure 1, the overnight nominal interest rate in Japan has stayed near zero since the fourth quarter of 1995 , providing approximately twenty years of data on the ZLB period.

\footnotetext{
${ }^{6}$ The Jorda projection method does not require us to use control variables in equation (2) if shock $k_{t}$ is exogenous and serially uncorrelated. However, additional controls help reduce the variance of residuals making the standard errors of $\beta_{h}^{x}$ smaller. This is why we add $\psi_{h}^{x}(L) y_{t-1}$. We also verify in the Appendix that the results do not change considerably if we include lags of shock .
} 
Second, during the ZLB period, Japan has experienced both recessions and booms. As a result, we can potentially see if the estimated multiplier is driven by the non-linear effects of government spending in different states of the business cycle. In Figure 1, we plot the growth rate of output per capita in Japan, taken from the National Accounts, along with the recession dates classified by the Cabinet Office. There are four business cycles after 1995 and three in the period between 1980 and 1995. This feature makes Japan an important case to study because the ZLB periods in other countries often coincide with recessions or wars, making it difficult to distinguish the effects of government spending in the ZLB period from those during other events.

We exploit a rich quarterly data set that includes forecasts of government spending. Unlike the United States, Japan has short surveys of professional forecasters that contain little or no information about government spending. Therefore, previous studies on Japan such as that by Auerbach and Gorodnichenko (2014) rely on semiannual forecasts from the OECD (starting in 1985) and the IMF (starting in 2003) to make inferences about unexpected changes in government spending. An important difference in our study is that we obtain quarterly forecast data produced by the JCER for many macroeconomic variables, including government spending, output, and the GDP deflator. This data set starts in 1967Q1 and contains several forecast horizons, ranging from nowcast to eight-quarters-ahead forecasts (forecasts of horizons longer than four quarters are not published regularly). The JCER publishes this data set every quarter, except during 197295, 1999-2002, and 2004-06, when the forecast was released in three of the four quarters. In the quarters without updated forecast data, we assume that there were no revisions to the forecasts; the one-quarterahead forecast is replaced by the two-quarters-ahead forecast published in the previous quarter (that is, $F_{t-1} \Delta \ln G_{t} \equiv F_{t-2} \Delta \ln G_{t}=F_{t-2}\left[\ln G_{t}-\ln G_{t-1}\right]$, where $F_{t-j} \Delta \ln G_{t}$ denotes the forecast of quarterly growth rate of per-capita government spending made $j$ quarters before). ${ }^{7}$ We plot in Figure 2 our one-quarter-ahead forecast of the four-quarters growth rate of government spending, $F_{t-1}\left(\ln G_{t}-\ln G_{t-4}\right)$, along with the realized government spending, $\ln G_{t}-\ln G_{t-4}$. Although the forecast misses some of the fluctuations, such as those in the early 2000s, the one-quarter-ahead forecast tracks the actual data relatively well. This suggests that the realized government spending may have some predictable components, and including these forecast data in the estimation can help us obtain a purer measure of unexpected government spending shocks. We show in Section 4.3 that these forecast data are indeed important to control for the timing of the spending and can affect the estimated multipliers.

Consistent with previous literature on fiscal multipliers, we construct data for government spending (or

\footnotetext{
${ }^{7}$ An alternative way to fill in the missing data is to use the nowcast, or an average of the nowcast, $F_{t} \Delta \ln G_{t}$, and two-quartersahead forecast $F_{t-2} \Delta \ln G_{t}$. Using these alternative series for forecasts yields the same results as the baseline.
} 
government purchases) as the sum of adjusted government consumption and public investment. Adjusted government consumption is calculated as total government consumption excluding transfer of goods. The average shares of "adjusted government consumption" and public investment in total GDP are about 11 percent and 8 percent, respectively. We discuss the construction of these adjusted series in Appendix 7. As plotted in Figure 1, government spending in Japan is volatile over the entire period between 1980Q2 and 2014Q1. The standard deviation of the growth rate of government spending is 1.73 times larger than that of output in Japan, compared to 1.21 in the United States, which potentially helps to precisely estimate the effects of government spending. Most of the variation in government spending comes from public investment: the standard deviation of the growth rate of public investment is four times larger than that of government consumption, as can be seen in Figure A1 in the online Appendix. Tax data, taken from the National Accounts starting in 1980Q1, are the sum of direct and indirect taxes less subsidies, which is almost identical to the tax data constructed by Doi, Hoshi, and Okimoto (2011). All variables are per capita and deflated by the GDP deflator. We provide links to all data sources in Appendix 7.

We define the normal period as 1980Q1 to 1995Q3 and the ZLB period as 1995Q4 to 2014Q1. Although the earliest start date for our data with forecasts is 1967Q1, we choose the start of the normal period as 1980Q1 for three reasons. First, the official definition of government spending data changes in Japan in 1980. Second, although we adjust our government spending series and extend the data to before 1980, there is a break in the monetary policy regime when Japan switched from a fixed nominal exchange rate regime to a floating exchange rate regime in 1973. According to empirical evidence in Ilzetzki, Mendoza, and Végh (2013), the fiscal multipliers in a fixed exchange rate regime are higher than those in a flexible exchange rate regime. ${ }^{8}$ Since we focus on periods with homogeneous monetary policy, we exclude the fixed exchange rate regime period before 1973. Third, the 1973 oil price spike created a large change in the aggregate price level and affected real government spending, which can bias the estimates of the multipliers. ${ }^{9}$ Therefore, we restrict our attention to the normal period, 1980Q1-1995Q3. We note that the baseline result presented below does not change if the normal period starts after the oil price shocks in 1975Q1. The ZLB period is from 1995Q4 to 2014Q1, when the short-term nominal interest rate falls to 0.25 percent and stays under 0.6 percent. We then estimate the impulse response functions using equation (2) and multipliers using equation (3) for both periods.

\footnotetext{
${ }^{8}$ A typical Open-Economy New Keynesian model can generate such a result under certain conditions. See, for example, Wieland (2012) and Fujiwara and Ueda (2013).

${ }^{9}$ To the extent that government spending is determined in nominal terms, a large unexpected change in the current price level can bias the identification of government spending shocks using nominal government spending deflated by the current price level. We find that the estimated multiplier for the normal period starting in 1973Q1 is slightly higher than the baseline estimates at longer horizons. However, when we control for this change by deflating nominal government spending by a smoothed measure of inflation or one-quarter lagged inflation, the estimate for the multiplier is similar to that in the baseline.
} 


\section{Output Multipliers During and Outside of the Zero Lower Bound}

This section first discusses the extracted shocks from our estimation and their relevance as an instrument for estimating multipliers. We then present the estimates of output multipliers in the ZLB and the normal periods, including the robustness of the estimates to alternative specifications.

\subsection{Extracted Shocks}

Figure 3 plots the extracted government spending shocks, $\widehat{\varepsilon}_{t}$, from equation (1). There is no noticeable difference between the normal and ZLB periods in terms of the sizes and the frequency of the shocks. Additionally, government spending variation during the ZLB period occurs not only during recessions but also during expansions. The extracted shocks are substantially volatile over time.

Since our extracted government spending shocks, $\widehat{\varepsilon}_{t}$, are the instrument for the estimates of the multipliers in equation (3), we test whether the instrument is relevant. To take into account possible serial correlations of the errors, we follow Ramey and Zubairy (2016) and apply the weak instrument tests in Olea and Pfueger (2013) for every horizon in the normal and the ZLB periods. Figure 4 plots the F-statistics obtained in the tests along with the thresholds for 5- and 10-percent critical values for testing the null hypothesis that the two-stage least squares bias exceeds 10 percent of the ordinary least squares (OLS) bias. The first-stage regression includes all the standard controls in four lags. In both the normal and the ZLB periods, the estimated shocks are highly relevant at very short horizons. The F-statistics fall below the thresholds at horizons longer than one year. This result is consistent with the tests conducted on U.S. data by Ramey and Zubairy (2016), who also find that the shocks obtained from the Blanchard and Perotti (2002) identification have lower F-statistics at longer horizons. To take into account that the instrument may be weak at longer horizons, we later test the differences in the output multipliers using both standard statistics and Anderson and Rubin (1949) statistics.

\subsection{Baseline Estimates}

We first consider the responses of government spending and output to an unexpected increase in government spending by 1 percent of output in period 0 . All of the results below are presented with one-standarddeviation error bands, unless otherwise stated. As plotted in Figure 5, output increases on impact and up to two years in the ZLB period; it increases slightly on impact and then decreases significantly in the normal period. The one-standard-deviation confidence interval bands for these estimates do not overlap with each other at shorter horizons. At the same time, the responses of government spending in the normal period are 
similar to those in the ZLB period.

To take into account the dynamics of the government spending response, we estimate the output multiplier. Figure 6 plots the output multipliers and their confidence bands in both the normal and ZLB periods. The point estimate of the output multiplier in the ZLB period is larger than zero at all horizons, larger than one, and larger than that in the normal period. The estimate of the output multiplier in the normal period is 0.6 on impact. This number is in line with previous estimates for the United States and other countries. The output multiplier in the ZLB period is 1.5 on impact—more than twice as large as the on-impact multiplier in the normal period. This multiplier is larger than that documented in the baseline estimation of Ramey and Zubairy (2016), but it is similar to their estimate when they exclude the World War II period. The on-impact multipliers in both the normal and ZLB periods are significantly larger than zero at the 5 percent level. The differences between the multipliers in the normal period and ZLB periods are pronounced at all horizons. While the output multiplier in the normal period turns negative after five quarters, the output multiplier in the ZLB period increases to about two after one year. The one-standard-deviation confidence bands of the multipliers do not overlap each other. Note that the results of the weak instrument test suggest that the estimates at longer horizons can be biased.

To formally test whether the output multipliers in these two periods are statistically different from each other, we estimate the following specification:

$$
\begin{aligned}
\sum_{j=0}^{h} x_{t+j}=I_{t-1} & \times\left[\alpha_{A, h}+M_{A, h}^{x} \sum_{j=0}^{h} \frac{G_{t+j}-G_{t-1}}{Y_{t-1}}+\psi_{A, h}(L) y_{t-1}\right] \\
& +\left(1-I_{t-1}\right) \times\left[\alpha_{B, h}+M_{B, h}^{x} \sum_{j=0}^{h} \frac{G_{t+j}-G_{t-1}}{Y_{t-1}}+\psi_{B, h}(L) y_{t-1}\right]+\varepsilon_{t+h}^{x}, \quad \text { for } h=1,2, \ldots,
\end{aligned}
$$

where $I_{t}$ is one if the economy is in the ZLB in period $t$ and zero otherwise, and subscripts $A$ and $B$ indicate the ZLB and normal periods. As in equation (3), we instrument changes in government spending with $\widehat{\varepsilon}_{t}$ obtained in equation (1). We test the hypothesis that the multipliers in the ZLB and normal periods are the same at each horizon: that is, $M_{A, h}^{x}=M_{B, h}^{x}$. Table 1 reports HAC $p$-values for this test at various horizons. We also include the $p$-values of Anderson and Rubin (1949) to account for the fact that the instrument may be weak at longer horizons. We plot in Figure 6 the differences between the multipliers across all horizons between zero and ten quarters and their confidence bands. The 95 percent confidence interval does not include zero. The Anderson and Rubin (1949) $p$-values are slightly higher than the standard $p$-values, but they are all below 0.1, suggesting that the difference is statistically significant at both shorter and longer horizons. 


\subsection{Importance of Forecast Data}

Controlling for forecast data is important for our analysis. To demonstrate this, we compare the baseline estimates of the output multipliers in the normal and ZLB periods with those estimated without forecast

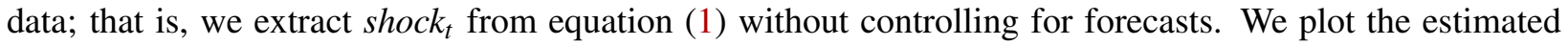
multipliers without forecast data and the baseline results in Figure 7. Controlling for the information that agents have about future government spending tends to make the point estimates of the output multiplier larger. This result is similar to the findings for the United States in Auerbach and Gorodnichenko (2012a). Without controlling for expectations, one would overstate the effects of government spending in the ZLB period relative to those in the normal period. For example, government spending is almost four times more expansionary in the ZLB period than in the normal period on impact. These results suggest that forecast data can change the estimated multipliers in a non-trivial way and controlling for expectations is important.

In Figure A6 in the online Appendix, we illustrate that the forecast data predicts government spending shocks obtained using only lagged macroeconomic variables. This predictability is more pronounced in the normal period than in the ZLB period. This last observation may explain why the output multiplier changes more in the normal period when we exclude forecast data than in the ZLB period, as can be seen in Figure 7.

\subsection{Robustness}

We perform several robustness checks of the baseline results. We summarize them here and provide more details in Appendix A. Because of the importance of the expectations effect, we add more control variables that can provide additional information about anticipated government spending in equation (1). Specifically, we add output forecasts, the OECD and the IMF government spending forecasts, and a host of other lagged macroeconomic variables, such as the index of leading indicators and orders received for public construction. The results remain close to the baseline.

We also examine how variations in the baseline specification affect our estimates of the multipliers. We include a quadratic time trend. We normalize changes in government spending and GDP in equations (2) and (3) by a measure of potential output instead of actual output. We address the generated regressors problem by estimating one-equation specification instead of splitting the estimation into two stages. We estimate a structural vector autoregression (SVAR) instead of the Jorda projection method. The point estimates and the standard errors estimated from these specifications remain close to the baseline.

Finally, we estimate a fifteen-year rolling-window regression instead of splitting our sample into the 
ZLB and the normal periods. We show that the output multipliers at various horizons increase around the start of the ZLB period in 1995.

\section{Other Variables Multipliers}

We have shown that the output multipliers are different in the ZLB and normal periods. It is natural to expect that the difference should be reflected in the responses of components of output and other variables related to output. In this section, we examine the multipliers of private aggregate consumption, investment, and the unemployment rate in the ZLB period and compare them with those in the normal period.

\subsection{Private Consumption and Investment}

The effects of government spending shocks on private consumption and investment can be computed by estimating equation (3) for consumption and investment. For example, the consumption multiplier $M_{h}^{C}$ is obtained by estimating

$$
\sum_{j=0}^{h} \frac{C_{t+j}-C_{t-1}}{Y_{t-1}}=\alpha_{h}^{C}+M_{h}^{C} \sum_{j=0}^{h} \frac{G_{t+j}-G_{t-1}}{Y_{t-1}}+\psi_{h}^{C}(L) y_{t-1}+\varepsilon_{t+h}^{x}, \quad \text { for } h=0,1,2, \ldots
$$

where the instrument for the cumulative changes in government spending is $\widehat{\varepsilon}_{t}$ from (1). We add four lags of consumption to the vector of standard controls, which we previously defined. The private investment multiplier is estimated in the same manner.

Figure 8 plots the cumulative multipliers of consumption and investment. The consumption multiplier is positive in the ZLB period, while it is negative in the normal period at one-year and two-year horizons. The investment multiplier in the ZLB period is also positive and higher than that in the normal period at most horizons other than on impact. As indicated in Table 2, the consumption multiplier is significantly larger in the ZLB period than in the normal period at the 1 percent significance level. The difference in the investment multipliers is not statistically significant on impact, but it is significant with a $p$-value of about 0.01 after four and eight quarters.

\subsection{Unemployment}

We examine the responses of the labor market to a government spending shock by estimating a version of equation (3) for the unemployment rate. Analogous to our definition of the output multiplier, we define the multiplier of the unemployment rate as the cumulative percentage point change in the unemployment rate 
in response to a change in government spending by 1 percent of output at each horizon ${ }^{10}$ We measure the unemployment rate multiplier in both the ZLB and normal periods, and we plot the cumulative multipliers of the unemployment rate in Figure 9. During the normal period, the unemployment rate does not respond much after an increase in government spending by 1 percent of output. In contrast, in the ZLB period, the unemployment rate decreases substantially by 0.1 percentage points on impact and further to 0.5 percentage points a year after an increase in spending by 1 percent of output. The drop in the unemployment rate in the ZLB period is significantly different from zero at all horizons. Furthermore, the confidence intervals of the unemployment rate multipliers in the ZLB and normal periods do not overlap across all horizons. We formally test the difference in the unemployment rate multipliers and report results in Table 2 . The difference is significant at the 5 percent level at horizons between one and eight quarters after the shock. ${ }^{11}$

\section{What Explains the Larger Output Multiplier at the Zero Lower Bound?}

We investigate several hypotheses that can potentially explain the larger output multiplier in the ZLB period than in the normal period. First, we examine the mechanism in New Keynesian models by documenting the effects of government spending on inflation, expected inflation, and nominal interest rates. Second, we discuss whether the effects of government spending in recessions or the differences in the tax rates in the two periods can explain our empirical findings. Third, we relax the Blanchard-Perotti identification assumption to examine how it may explain the differences in the multipliers in the two periods. Lastly, we investigate whether the composition of government spending in the two periods may explain the difference in the multipliers.

\subsection{The Expected Inflation Channel}

A typical New Keynesian model provides a possible explanation for the difference in the output multiplier in the ZLB and normal periods. Higher government spending increases the current and future marginal costs of production for firms and, hence, current and future inflation. In the normal period, the real interest rate - the nominal interest rate net of expected inflation—goes up because of a strong central bank reaction, reducing consumption and investment. In the ZLB period, the real interest rate drops because the central

\footnotetext{
${ }^{10}$ Alternatively, one can define the unemployment multiplier by the absolute change in the unemployment rate after $h$ quarters normalized by the cumulative government spending changes. Both measures of unemployment multipliers imply significantly different behavior of the unemployment rate in the normal and the ZLB periods. See Monacelli, Perotti, and Trigari (2010) for empirical and theoretical analyses of unemployment multipliers.

${ }^{11}$ We also estimate the multipliers for net exports; the real effective exchange rate; and components of consumption and investment including durables, non-durables, semi-durables, and services consumption; as well as residential and non-residential investment using the same specification. The results are reported in the online Appendix, Figures A12 and Figure A13.
} 
bank does not change the nominal interest rate, which stimulates consumption and investment. In this section, we document the responses of inflation, inflation expectations, and the nominal interest rates after a government spending shock to shed light on this mechanism.

Inflation. We estimate the inflation multiplier, defined as the impulse response of the nominal price index divided by the cumulative change in government spending, from equation (3). The vector of controls includes four lags of the inflation rate, the standard controls, and the five-year nominal interest rate. The results do not change if we do not include the interest rate in the controls, or if we use the ten-year interest rate on government bonds. We estimate the responses of both the GDP deflator and the CPI measures of inflation.

We find mixed evidence on the response of inflation to unexpected government spending shocks. The first row of Figure 10 plots the multipliers of these two measures of inflation in both the normal and ZLB periods. Inflation calculated from the GDP deflator responds little to a positive government spending shock in both periods on impact. The cumulative inflation multiplier is about 0.1 percentage points at a two-year horizon in the ZLB period but negative in the normal period. Overall, the response of inflation is mild in both periods, and the one-standard-deviation confidence interval includes zero at short horizons. The CPI inflation multiplier is, however, considerably bigger than that calculated from the GDP deflator in the ZLB period. CPI inflation in the ZLB period responds positively on impact: an increase in government spending by 1 percent of output leads to a 0.68 percentage-point increase in CPI inflation in the ZLB period on impact. The response of CPI inflation in the normal period is -0.16 percentage points. In Appendix A.3, we estimate the inflation multipliers using a tax-adjusted CPI that takes into account changes in consumption taxes, core CPI, and tax-adjusted core CPI. We find similar results to those obtained using the CPI. We conclude that there is some evidence of a positive inflation response in the ZLB period.

Expected inflation. The difference in the responses of expected inflation in the ZLB and normal periods are more pronounced. The second row of Figure 110 plots the impulse responses of the four-quarters-ahead expected GDP deflator and CPI annual inflation rates to an increase in government spending by 1 percent of output. In the estimation, we control for four lags of the dependent variables, the standard controls, and the five-year nominal interest rate. The on-impact responses of GDP deflator inflation expectations are negative, but the one-standard-deviation confidence interval includes zero in both the normal and ZLB periods. In the next two quarters, the inflation expectations response is negative in the normal period, while it is positive in the ZLB period. Inflation expectations increase by 0.65 percentage points after two quarters 
in the ZLB period but decrease by 0.25 percentage points in the normal period. The differences between inflation expectations in the normal and ZLB periods are also present when we look at the CPI. At the onequarter horizon and longer, the CPI inflation expectation responses are positive and substantially different from zero in the ZLB period, but are negative in the normal period. We reject the joint null hypothesis that the responses of inflation expectations (both GDP deflator and CPI) at all horizons do not differ across the two subsamples at the 5-percent confidence level.

Nominal interest rates. The last row of Figure 10 plots the impulse responses of the overnight (shortterm) nominal interest rate and the yield on a ten-year government bond to an increase in government spending by 1 percent of output. These responses are estimated by adding to the baseline specification (2) four lags of the dependent variable, the standard controls, and the inflation rate. We include trend $_{t}$ to control for the observed decline in the nominal interest rate over time. ${ }^{12}$ We report the estimated results with a quadratic trend, but the results do not change if we include a linear trend. In the normal period, the short-term interest rate increases to 0.37 percentage points at a one-year horizon in response to an increase in government spending by 1 percent of output. In the ZLB period, the short-term interest rate does not react to government spending shocks. This is consistent with the idea that the central bank is not responsive to government spending shocks during the ZLB period. These results, together with the response of expected inflation, suggest that the short-term real interest rate increases more in the normal period than in the ZLB period.

The impulse response of the ten-year nominal interest rate is generally not statistically different from zero at the conventional levels and increases after ten quarters in both the normal and ZLB periods. Additionally, the point estimates of the response of the long-term rates is higher in the ZLB period than in the normal period.

To summirize, there is some evidence that inflation and expected inflation increase more in the ZLB than in the normal period, while the short-term nominal interest does not change in the ZLB period and increases in the normal period. These results are consistent with the predictions of a typical New Keynesian model. At the same time, the behavior of the long-term nominal interest rate is at odds with a New Keynesian model in which the expectations hypothesis holds. It is important to note that recent theoretical papers reduce the importance of the expectations channel but propose alternative mechanisms that generate differences in the output multipliers across the ZLB and normal periods. For example, Rendahl (2014) shows that a New

\footnotetext{
${ }^{12}$ There is a clear trend in the nominal interest rate in the normal period in Japan. If we exclude trend in the specification, as reported in the online Appendix Figure A14, the responses of the nominal interest rate in the normal period become closer to zero. Note that we do not include trend in the estimation of the other variables because adding trend does not alter the results.
} 
Keynesian model, augmented with a search-and-matching friction in the labor market, can generate a higher output multiplier in the ZLB period even with a zero or negative expected inflation response, as long as there is a difference in the responses of the short-term nominal interest rate in the ZLB and normal periods.

A number of additional mechanisms may explain the difference in the output multiplier in the ZLB and normal periods that we estimated. We explore some of those next.

\subsection{Output Multipliers in the ZLB Period and in Recessions}

Using U.S. and OECD data, Auerbach and Gorodnichenko (2012a,b) find that the output multiplier is larger than one in recessions and smaller than one in expansions. As the ZLB period often coincides with recessions, it is important to differentiate evidence from the ZLB period and evidence from recessions. This section shows that our estimated multiplier in the ZLB period may not be attributed to the larger effect of government spending in temporary recessions. We also discuss the possibility that a permanent recession that coincides with the ZLB period in Japan can explain our results.

In order to argue that our results are not likely to be driven by temporary recessions, we proceed as follows. First, we estimate the multipliers during booms and recessions in Japan between 1980Q1 and 2014Q1 by estimating a state-dependent version of the specification in equation (4), similar to Ramey and Zubairy (2016). The recession indicator, depicted as grey bars in Figure 1, is defined as recession quarters according to the Cabinet Office of Japan. Figure 11 plots the output multipliers in recessions and expansions and the difference between these two multipliers. The on-impact output multiplier in recessions is as large as 2.3; it is 0.8 in expansions. The differences in the multipliers in recessions and expansions are smaller at horizons longer than three quarters. The differences are also not statistically significant at longer horizons, as reported in Table 3. This result for Japan is qualitatively similar to that for the United States in Auerbach and Gorodnichenko (2012a) but with wider error bands. The results in this section do not change if we use the peak-to-trough recession classification of the OECD.

Since the multiplier in recessions is larger than in expansions, we would need more recessions in the ZLB than in the normal period in order to explain the larger multiplier in the ZLB period. However, this is not the case, as can be seen in Figure 1: 45 percent of the quarters in the normal period are in recession while only 30 percent in the ZLB period are recession. This implies that the multiplier during the ZLB period should be smaller than the multiplier during the normal period if the only fundamental difference is between the values of the multipliers in recessions and expansions. Moreover, the extracted shocks plotted in Figure 3 suggest that most government spending variations during the ZLB do not occur during recessions, and most government spending variations during the normal period do not occur during booms. Therefore, 
it is unlikely that the difference in multipliers across recessions and booms can explain the difference in multipliers between the ZLB and normal periods that we estimate.

Our analysis does not rule out the possibility that a long period of slack, coinciding with the ZLB period, can potentially explain the estimated high output multiplier in the ZLB period. As plotted in Figure 12, the unemployment rate, which is sometimes used as a measure of slack, is permanently higher in the ZLB period than in the normal period.

However, there are two reasons to believe that the presence of the ZLB may still be important in explaining our results. First, as we showed above, the responses of expected inflation, short-term nominal interest rate, consumption, and investment in both ZLB and normal periods are consistent with the predictions of a typical New Keynesian model. Second, although the unemployment rate suggests an elevated level of slack in Japan during the ZLB period, we note that it is labor market tightness, not the unemployment rate, which should be used as an indicator of slack that affects the size of multipliers. There is no evidence that tightness changed permanently (see Figure 13).

The fact that tightness and not unemployment is the relevant measure of slack that affects the size of multipliers is a theoretical prediction of recent models that explain state-dependent multipliers (Michaillat, 2014; Michaillat and Saez, 2017). The intuition is based on a standard search-and-matching labor market model: in states with high tightness, government purchases crowd out private employment more than in states with low tightness. The government spending multiplier, therefore, is lower when tightness is higher. Additionally, when unemployment varies for a given level of tightness (e.g., when the Beveridge curve shifts), the output multiplier is predicted to remain the same.

While it is clear that the unemployment rate was substantially higher in the ZLB period in Japan than in the normal period, there is no apparent break in tightness that would signal the permanently higher amount of slack after 1995, as plotted in Figure 13. One possible explanation for this is the series of labor market reforms in the 1990s and 2000s that deregulated fixed-term labor contracts and likely shifted the Beveridge curve outward, increasing frictional unemployment without affecting tightness permanently (Hijzen et al., 2015). This suggests that tightness, not unemployment, may be a better proxy for labor market slack in Japan.

\subsection{Tax Rate}

Another possible explanation for the difference in the output multipliers in the ZLB and normal periods is that tax rates respond differently in the two periods. We estimate the responses of average tax rates in the normal and ZLB periods after a government spending shock. We define the average tax rate $T_{t}$ as a ratio 
of tax revenues to GDP. The cumulative multipliers of the average tax rate are estimated from equation (3), with the variable of interest $T_{t+h}$. We plot the multipliers of the average tax rate in the last panel of Figure 14. We find that in response to an increase in government spending by 1 percent of output, the average tax rate increases in both the normal and ZLB periods. The increase in the tax rate is larger in the ZLB period than in the normal period at horizons longer than one year. For example, the cumulative response of the average tax rate is 0.5 percentage points in the ZLB period after two quarters, while it is near zero in the normal period. At longer horizons, the cumulative response of the average tax rate is more negative in the normal period than in the ZLB period. This result suggests that to the extent that an increase in average tax rate is contractionary, the different responses of the average tax rate in the two periods are not likely to explain the observed difference in the output multipliers.

The timing of tax rate changes may matter as well. For example, in the case of an expected future increase in distortional income taxes, people may increase their current labor supply to get the most out of lower taxes. As a result, one can expect that the output multiplier is larger in the short horizons and smaller in the longer horizons. Although we observe an increase in the tax rate multiplier during the first six quarters in Figure 14 in the ZLB period, we also observe an increase in the output multiplier in Figure 6, contrary to the logic just presented.

\subsection{Automatic Stabilizer}

To obtain our main results, we assumed that variations in output do not automatically change contemporaneous government spending; that is, the elasticity of government spending with respect to current output $\eta_{G, Y}$ is zero. The idea behind this assumption, as Blanchard and Perotti (2002) discuss, is that the government needs some time to change government spending in response to current economic conditions. To examine whether this assumption can explain the difference in the multipliers between the ZLB and normal periods, we assume a non-zero elasticity of government spending to current output. Specifically, we change the first step of our empirical procedure, equation (1), as follows:

$$
\Delta \ln G_{t}=\alpha+\eta_{G, Y} \Delta \ln Y_{t}+\gamma F_{t-1} \Delta \ln G_{t}+\psi(L) y_{t-1}+\varepsilon_{t}
$$

and fix $\eta_{G, Y}$ to be either -0.1 or 0.1 . Consistent with the analysis of Caldara and Kamps (2012), we find that the on-impact multiplier is lower than our baseline estimates when $\eta_{G, Y}=0.1$. The on-impact multipliers in the ZLB and normal periods are 1.4 and 0.5, respectively. The on-impact multipliers in both periods are higher than the baseline when the elasticity, $\eta_{G, Y}=-0.1: 1.7$ in the ZLB period and 0.7 in the normal 
period, respectively. This result suggests that our estimated output multiplier is biased if the true elasticity $\eta_{G, Y}$ is non-zero. However, this bias has the same sign and approximately the same size across the ZLB and normal periods. As a result, the failure of the Blanchard and Perotti (2002) identification assumption alone may not explain the difference in the estimated output multipliers across the normal and ZLB periods. Only when we assume substantially different elasticities in the ZLB and normal periods can the automatic stabilizer effect alone explain the difference between the estimated output multipliers. We find that $\eta_{G, Y}$ should be -0.7 in the normal period for the on-impact multiplier in the normal period to be almost the same as our baseline on-impact multiplier in the ZLB period (1.5). Alternatively, if $\eta_{G, Y}=0.5$ in the ZLB period, the on-impact multiplier in the ZLB period equals the on-impact output multiplier in the normal period in our baseline estimation (0.6).

\subsection{Composition of Government Spending}

Another potential explanation for the difference in the multipliers between the ZLB and normal periods is that the investment-consumption composition of government spending shocks has changed over time (Bouakez, Guillard, and Roulleau-Pasdeloup, 2017). To examine this explanation, we document the responses of government investment and consumption to government spending shocks and plot the results in Figure 15. In response to an increase in total government spending by 1 percent of output, government investment increases by 0.8 percent of output on impact for both the ZLB and normal periods. The paths of the responses of government investment are similar across the two periods. The paths of government consumption are also similar across these two periods with an increase of about 0.2 percent of output on impact.

If there were a substantial difference in the responses of public consumption and/or public investment after a government spending shock in the normal and ZLB periods, this could potentially account for some difference in the multipliers that we estimate. However, this is not likely to explain the difference in the output multipliers that we estimate given that there is no large difference in the responses.

\section{Conclusion}

We use information about the ZLB period in Japan to estimate the effects of government spending changes on output. We control for expected government spending to identify its unexpected changes. Our point estimate of the output multiplier is larger than one in the ZLB period, and larger than the multiplier in the normal period. On impact, the output multiplier is 1.5 in the ZLB period and 0.6 in the normal period. 
Furthermore, government spending crowds in private consumption and investment in the ZLB period, in contrast with the crowding-out effects in the normal period. We estimate a more positive response in the ZLB period for some measures of inflation. Additionally, the ex-ante short-term real interest rate decreases by more in the ZLB period than in the normal period. Our analysis suggests that the expected inflation channel can be important in explaining the larger multiplier in the ZLB period.

\section{References}

Alesina, Alberto, Carlo Favero, and Francesco Giavazzi. 2015. "The output effect of fiscal consolidation plans." Journal of International Economics 96:S19-S42.

Anderson, T.W. and H. Rubin. 1949. "Estimation of the Parameters of a Single Equation in a Complete System of Stochastic Equations.” Annals of Mathematical Statistics 20:46-63.

Aruoba, S Boragan, Pablo Cuba-Borda, and Frank Schorfheide. 2016. "Macroeconomic Dynamics Near the ZLB: A Tale of Two Countries.” Working paper.

Auerbach, Alan J and Yuriy Gorodnichenko. 2012a. "Fiscal multipliers in recession and expansion." In Fiscal Policy after the Financial crisis. University of Chicago Press, 63-98.

—. 2012b. "Measuring the output responses to fiscal policy." American Economic Journal: Economic Policy 4:1-27.

—. 2014. "Fiscal Multipliers in Japan.” Working paper, National Bureau of Economic Research.

Barro, Robert J. 1981. “Output effects of government purchases.” Journal of Political Economy 89:10861121.

Barro, Robert J. and C. J. Redlick. 2011. "Macroeconomic Effects From Government Purchases and Taxes." The Quarterly Journal of Economics 126 (1):51-102.

Baxter, Marianne and Robert G King. 1993. "Fiscal Policy in General Equilibrium.” American Economic Review 83 (3):315-34.

Blanchard, Olivier and Roberto Perotti. 2002. "An empirical characterization of the dynamic effects of changes in government spending and taxes on output." Quarterly Journal of Economics 107 (November):1329-1368.

Bouakez, Hafedh, Michel Guillard, and Jordan Roulleau-Pasdeloup. 2017. "Public investment, time to build, and the zero lower bound." Review of Economic Dynamics 23:60-79.

Bruckner, Marcus and Anita Tuladhar. 2014. "Local Government Spending Multipliers and Financial Distress: Evidence from Japanese Prefectures.” Economic Journal 124:1279-1316. 
Caldara, Dario and Christophe Kamps. 2012. "The Analytics of SVARs: A Unified Framework to Measure Fiscal Multipliers.” Working Paper.

Chodorow-Reich, Gabriel, Laura Feiveson, Zachary Liscow, and William Gui Woolston. 2012. "Does State Fiscal Relief during Recessions Increase Employment? Evidence from the American Recovery and Reinvestment Act." American Economic Journal: Economic Policy 4 (3):118-45.

Christiano, Lawrence, Martin Eichenbaum, and Sergio Rebelo. 2011. "When Is the Government Spending Multiplier Large?” Journal of Political Economy 119 (1):78 - 121.

Cohen, Lauren, Joshua Coval, and Christopher Malloy. 2011. "Do Powerful Politicians Cause Corporate Downsizing?” Journal of Political Economy 119 (6):1015-1060.

Coibion, Olivier and Yuriy Gorodnichenko. 2012. "What can survey forecasts tell us about informational rigidities?" Journal of Political Economy 120:116-150.

Coibion, Olivier, Marc Dordal i Carreras, Yuriy Gorodnichenko, and Johannes Wieland. 2016. "Infrequent but Long-Lived Zero-Bound Episodes and the Optimal Rate of Inflation.” Annual Review of Economics forthcoming.

Crafts, Nicholas and Terence C. Mills. 2012. "Fiscal Policy in a Depressed Economy: Was there a 'Free Lunch' in 1930s' Britain?" Unpublished paper.

Doi, Takero, Takeo Hoshi, and Tatsuyoshi Okimoto. 2011. "Japanese government debt and sustainability of fiscal policy." Journal of the Japanese and International Economies 25 (4):414-433.

Dupor, Bill and Rong Li. 2015. "The expected inflation channel of government spending in the postwar US.” European Economic Review 74:36-56.

Eggertsson, Gauti B. 2011. "What fiscal policy is effective at Zero interest rates?" NBER Macroeconomics Annual 25:59-112.

Farhi, Emmanuel and Iván Werning. 2012. "Fiscal Multipliers: Liquidity Traps and Currency Unions." NBER Working Papers 18381, National Bureau of Economic Research, Inc.

Fisher, Jonas D.M. and Ryan Peters. 2010. “Using Stock Returns to Identify Government Spending Shocks.” The Economic Journal 120 (544):414-436.

Fujiwara, Ippei and Kozo Ueda. 2013. “The fiscal multiplier and spillover in a global liquidity trap.” Journal of Economic Dynamics and Control 37 (7):1264-1283.

Hayashi, Fumio and Junko Koeda. 2014. "Exiting from QE.” NBER Working Paper No. 19938.

Hijzen, Alexander, Ryo Kambayashi, Hiroshi Teruyama, and Yuji Genda. 2015. "The Japanese labour market during the global financial crisis and the role of non-standard work: A micro perspective." Journal of the Japanese and International Economies 38:260-281. 
Ilzetzki, Ethan, Enrique G. Mendoza, and Carlos a. Végh. 2013. "How big (small?) are fiscal multipliers?" Journal of Monetary Economics 60 (2):239-254.

Jorda, Oscar. 2005. "Estimation and Inference of Impulse Responses by Local Projections." American Economic Review 95 (1):161-182.

Mertens, K. R. S. M. and M. O. Ravn. 2014. "Fiscal Policy in an Expectations-Driven Liquidity Trap." The Review of Economic Studies 81 (4):1637-1667.

Michaillat, Pascal. 2014. “A theory of countercyclical govenrment multiplier.” American Economic Journal: Macroeconomics 6 (1):190-217.

Michaillat, Pascal and Emmanuel Saez. 2017. “Optimal Public Expenditure with Inefficient Unemployment." Working paper.

Monacelli, T., R. Perotti, and A. Trigari. 2010. “Unemployment Fiscal Multipliers.” Journal of Monetary Economics 57 (5):531-553.

Mountford, Andrew and Harald Uhlig. 2009. "What are the effects of fiscal policy shocks?" Journal of Applied Econometrics 992 (April):960-992.

Nakamura, Emi and Jon Steinsson. 2014. "Fiscal Stimulus in a Monetary Union: Evidence from US Regions." American Economic Review 104 (3):753-92.

Olea, Jose Luis Montiel and Carolin Pfueger. 2013. “A Robust Test for Weak Instruments.” Journal of Business and Economic Statistics 13 (3):358-369.

Ramey, Valerie A. 2011a. "Can government purchases stimulate the economy?" Journal of Economic Literature 49 (3):673-685.

—. 2011b. "Identifying Government Spending Shocks: It's all in the Timing." The Quarterly Journal of Economics 126 (1):1-50.

Ramey, Valerie A and Sarah Zubairy. 2016. "Government spending multipliers in good times and in bad: Evidence from US historical data." Working paper.

Rendahl, Pontus. 2014. "Fiscal policy in an unemployment crisis." LSE Research Online Documents on Economics 58132, London School of Economics and Political Science, LSE Library.

Rognlie, Matthew. 2015. "What Lower Bound? Monetary Policy with Negative Interest Rates.” Working paper.

Shoag, Daniel. 2010. "The impact of government spending shocks: Evidence on the multiplier from state pension plan returns.” Working paper.

Stock, J. H. and M. W. Watson. 2007. “Why Has U.S. Inflation Become Harder to Forecast?” Journal of Money, Credit and Banking 39 (1):3-33. 
Watanabe, Tsutomu, Tomoyoshi Yabu, and Arata Ito. 2010. "Seidojyouhou wo mochiita zaiseijyousu no keisoku.” In Zaiseiseisaku to Syakaihosyo. Keio University Press.

Wieland, Johannes. 2012. "Fiscal Multipliers at the Zero Lower Bound: International Theory and Evidence." Working paper.

- 2013. "Are negative supply shocks expansionary at the zero lower bound?" Working paper.

Woodford, Michael. 2011. "Simple analytics of the government expenditure multiplier." American Economic Journal: Macroeconomics 3 (January):1-35. 


\section{Tables and Figures}

Table 1: Output Multipliers

\begin{tabular}{cccc}
\hline \hline & Normal & ZLB & $p$-value \\
\hline On impact & 0.61 & 1.54 & HAC: 0.02 \\
& $(0.23)$ & $(0.43)$ & AR: 0.09 \\
1 quarter & 0.53 & 1.93 & HAC: 0.01 \\
& $(0.20)$ & $(0.65)$ & AR: 0.06 \\
4 quarter & 0.12 & 2.67 & HAC: 0.00 \\
& $(0.58)$ & $(1.11)$ & AR: 0.06 \\
8 quarter & -0.56 & 1.70 & HAC: 0.00 \\
& $(0.34)$ & $(0.94)$ & AR: 0.08
\end{tabular}

Notes: The table reports the estimated cumulative output multipliers at different horizons in the normal and in the ZLB periods. The HAC robust and Anderson-Rubin $p$-values of the difference between the multiplier in the normal period and that in the ZLB period are reported in the last column. Numbers in parentheses are the HAC standard errors.

Table 2: Multipliers of Other Variables

\begin{tabular}{cccc|cccc}
\hline & Normal & ZLB & $p$-value & & Normal & ZLB & $p$-value \\
\hline Consumption & & & & Investment & & & \\
\hline On impact & 0.35 & 1.25 & 0.00 & On impact & -0.08 & -0.13 & 0.84 \\
& $(0.16)$ & $(0.39)$ & & & $(0.16)$ & $(0.13)$ & \\
4 quarter & -0.54 & 2.83 & 0.00 & 4 quarter & -0.05 & 0.93 & 0.01 \\
& $(0.56)$ & $(0.83)$ & & & $(0.24)$ & $(0.53)$ & \\
8 quarter & -1.00 & 2.19 & 0.00 & 8 quarter & -0.17 & 0.93 & 0.01 \\
& $(0.68)$ & $(0.50)$ & & Tax rate & $(0.22)$ & $(0.49)$ & \\
Unemployment & & & & & & \\
On impact & -0.03 & -0.09 & 0.01 & On impact & 0.02 & 0.10 & 0.91 \\
& $(0.02)$ & $(0.03)$ & & & $(0.25)$ & $(0.12)$ & \\
4 quarter & -0.05 & -0.50 & 0.00 & 4 quarter & 0.03 & 0.75 & 0.04 \\
& $(0.05)$ & $(0.16)$ & & & $(0.30)$ & $(0.38)$ & \\
8 quarter & -0.06 & $-0.60)$ & 0.00 & 8 quarter & -0.34 & 0.56 & 0.00 \\
& $(0.05)$ & $(0.27)$ & & & $(0.18)$ & $(0.42)$ & \\
\hline
\end{tabular}

Notes: The table reports the results of the multipliers on impact and at four- and eight-quarter horizons in the normal period (column "Normal") and in the ZLB period (column "ZLB"). The consumption, investment and unemployment rate multipliers are defined analogously to the output multiplier. The HAC robust $p$-value of the difference between the multiplier in the normal period and that in the ZLB period is reported in the " $p$-value" column. All numbers in parentheses are the HAC standard errors. 
Table 3: Output Multipliers in Recession and Expansion

\begin{tabular}{lccc}
\hline \hline & On impact & 4 quarter & 8 quarter \\
\hline Slackness & & & \\
Expansion & 0.78 & 0.91 & 0.49 \\
& $(0.29)$ & $(0.71)$ & $(1.32)$ \\
Recession & 1.97 & 2.53 & 0.86 \\
& $(0.60)$ & $(0.72)$ & $(1.39)$ \\
$P$-value of difference & 0.09 & 0.27 & 0.83 \\
\hline
\end{tabular}

Notes: This table reports the output multipliers in two regimes: recession and expansion. These regimes are classified based on the Japanese Cabinet Office. All numbers in parentheses are the standard errors. 
Figure 1: Nominal Interest Rate, Real GDP and Government Spending Growth Rates in Japan
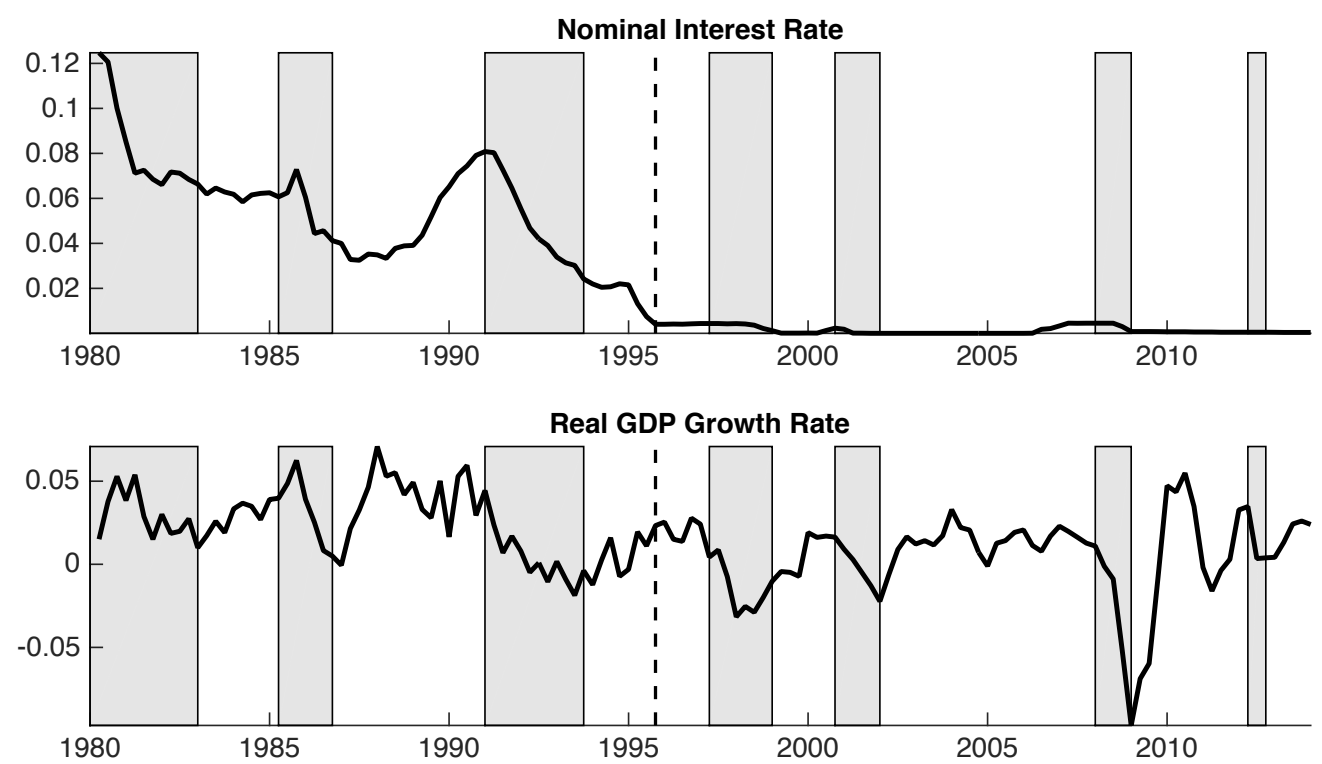

Real Government Spending Growth Rate

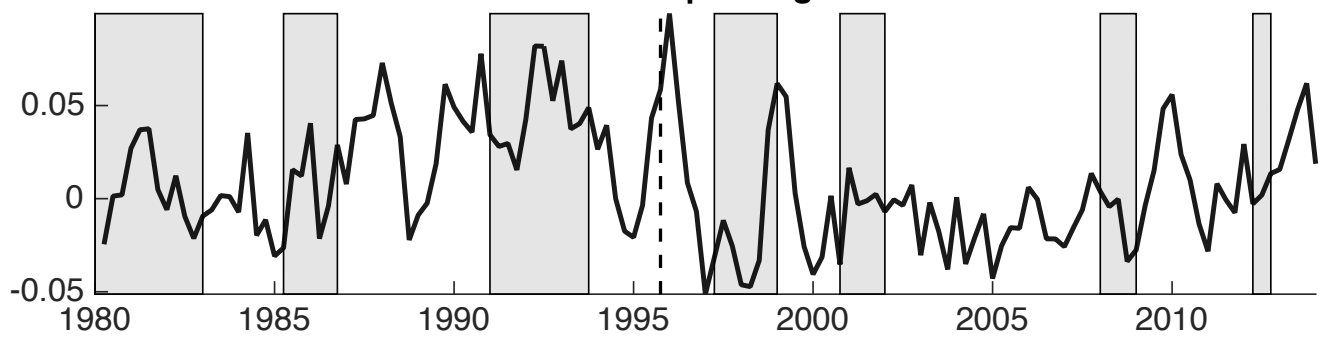

Notes: The shaded areas are Cabinet Office recession dates.

Figure 2: Government Spending Growth Rate: Actual and Forecast

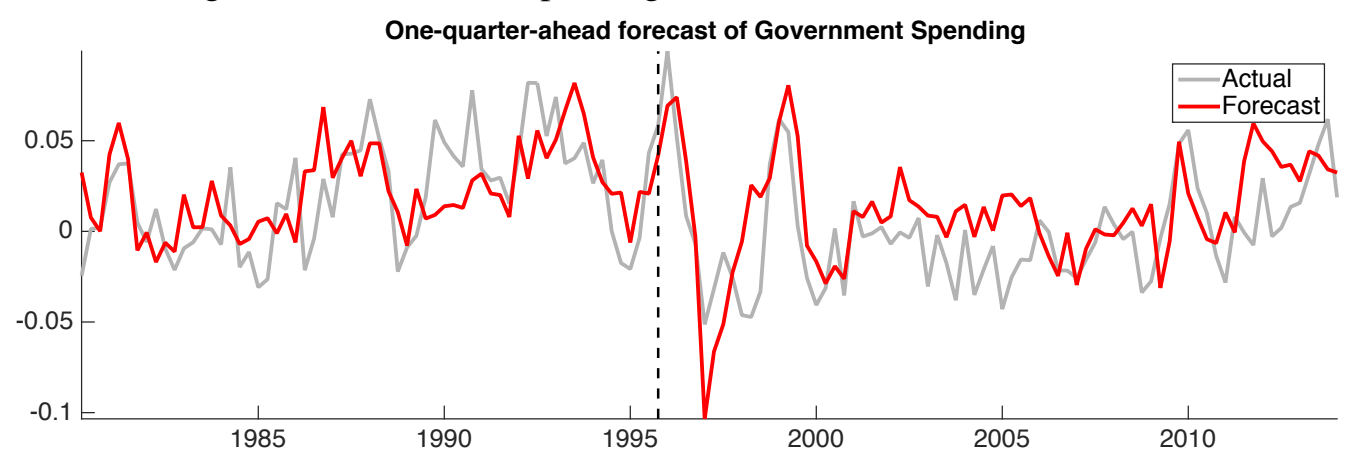

Notes: "Actual" denotes the realized government spending growth rate $\ln \left(G_{t} / G_{t-4}\right)$, and "Forecast" denotes the one-quarter-ahead forecast of government spending $F_{t-1} \ln \left(G_{t} / G_{t-4}\right)$ from the JCER. 
Figure 3: Extracted Government Spending Shocks $\widehat{\varepsilon}_{t}$

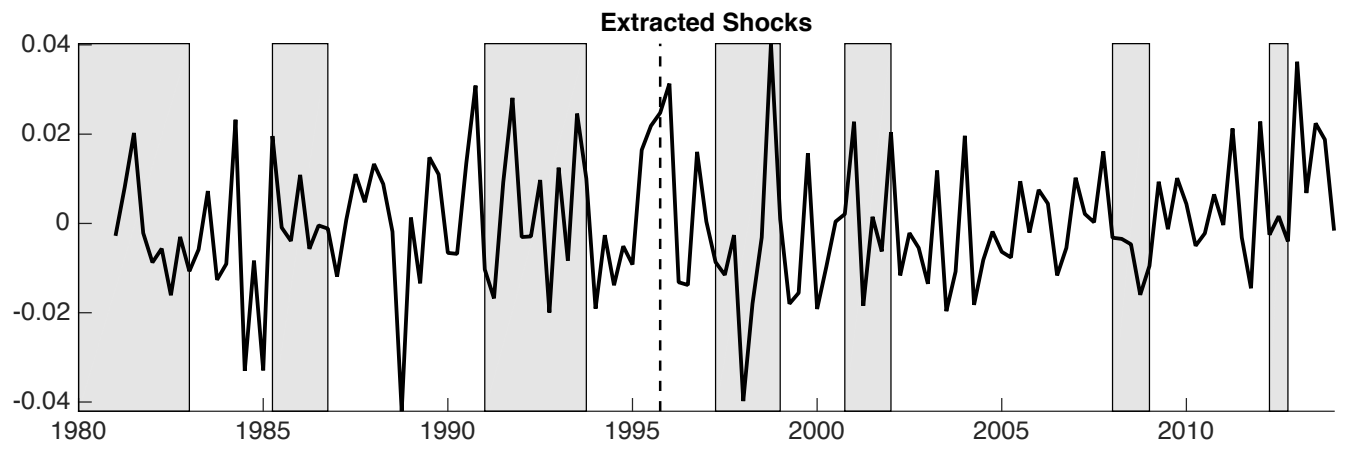

Notes: The extracted shocks series are estimated from equation (1).

Figure 4: Test of Weak Instrument

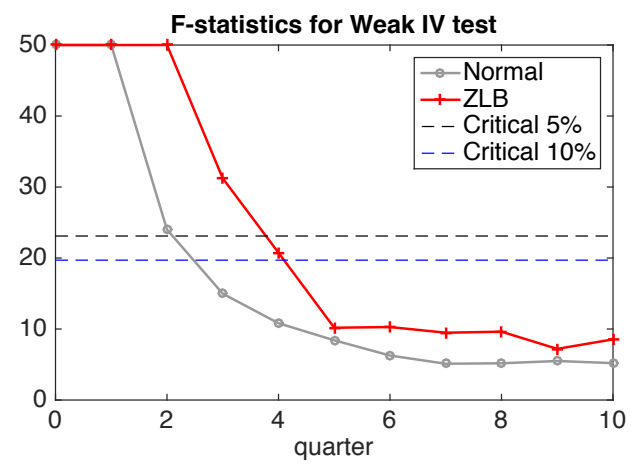

Notes: The graph reports the F-statistics, capped at 50, testing the weak instrument $\widehat{\varepsilon}_{t}$ in the first-stage estimation for equation (3). The threshold is 23.1 for one instrument for the 5 percent critical value for testing the null hypothesis that the two-stage least squares bias exceeds 10 percent of the OLS bias, and 19.7 for 10 percent critical value. All statistics are robust to heteroskedasticity and serial correlation.

Figure 5: Impulse Responses of Output and Government Spending
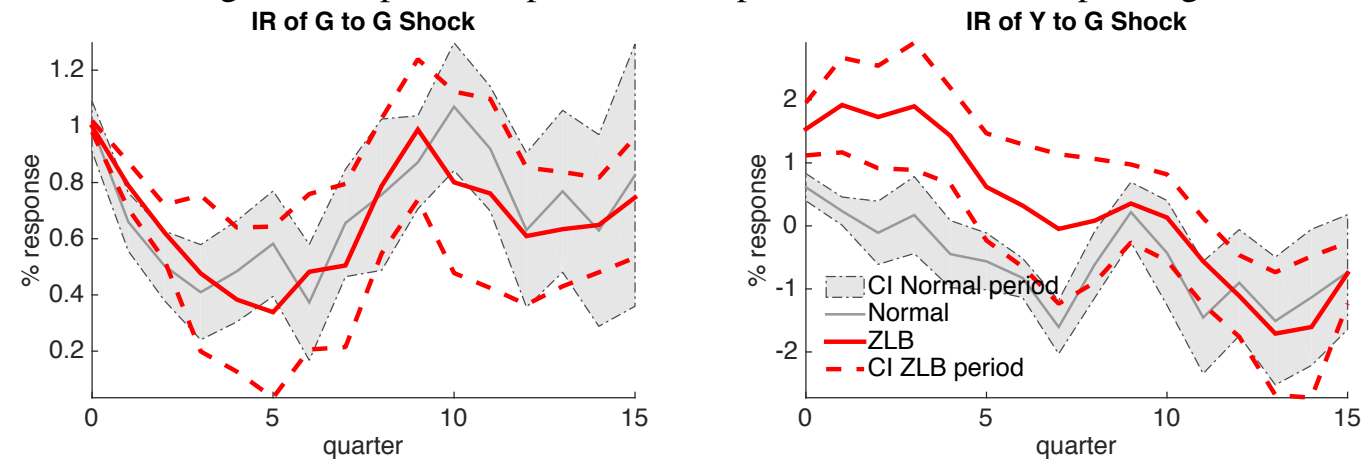

Notes: Impulse responses of output and government spending to an unexpected increase in government spending by 1 percent of output during normal and ZLB periods together with one-standard-deviation error bands. 
Figure 6: Output Multipliers and the Difference in the Multipliers

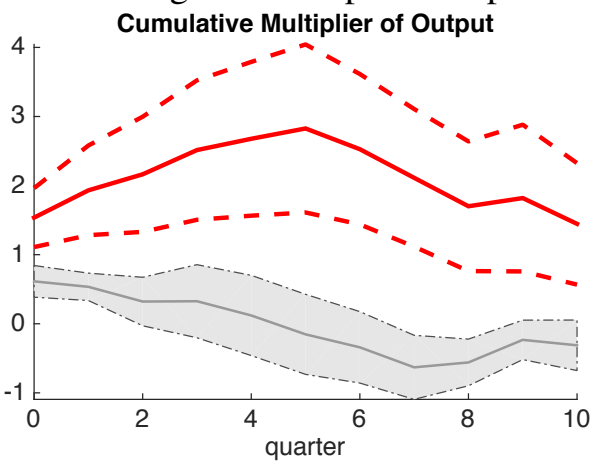

Difference of Multipliers

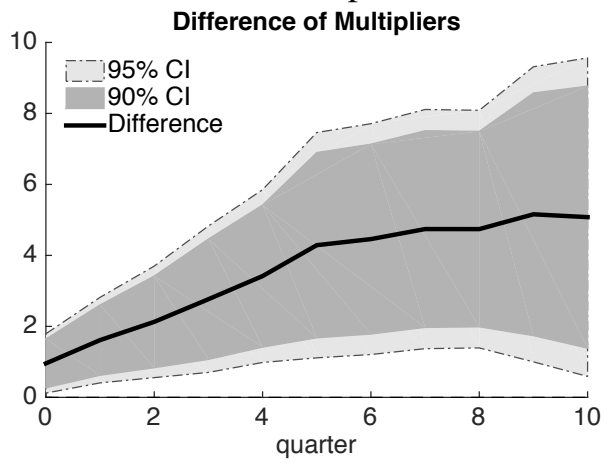

Notes: Output multipliers during normal and ZLB periods (left panel), and their difference (right panel). The borders around point estimates on the left panel are one-standard-deviation error bounds.

Figure 7: Output Multipliers with and without Forecast Data
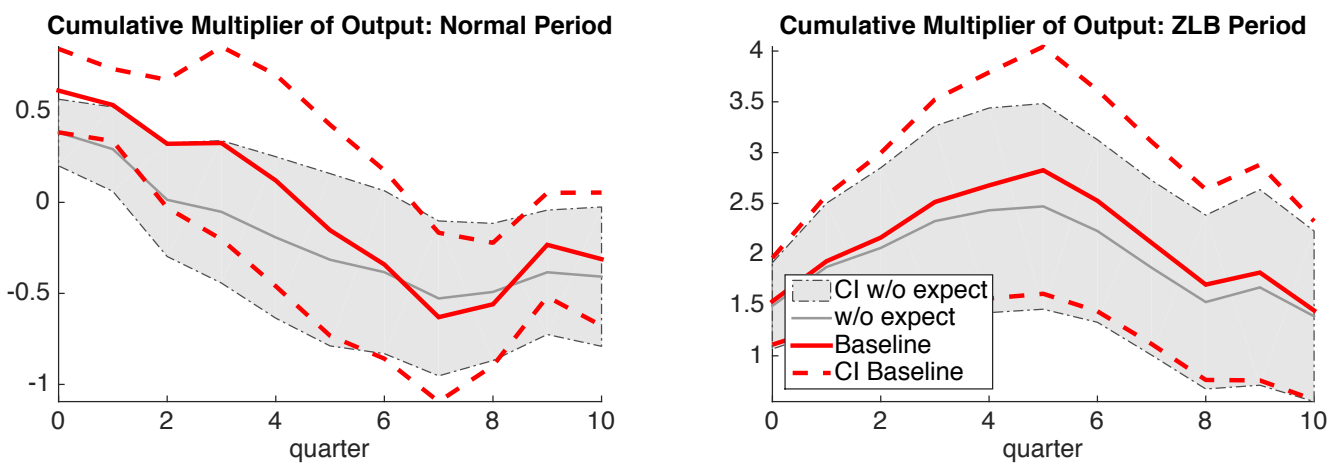

Notes: The left (right) figure plots the output multipliers in the normal (ZLB) period estimated in the baseline and estimated without forecast data (the grey lines), together with their one-standard-deviation confidence intervals.

Figure 8: Private Consumption and Investment Multipliers
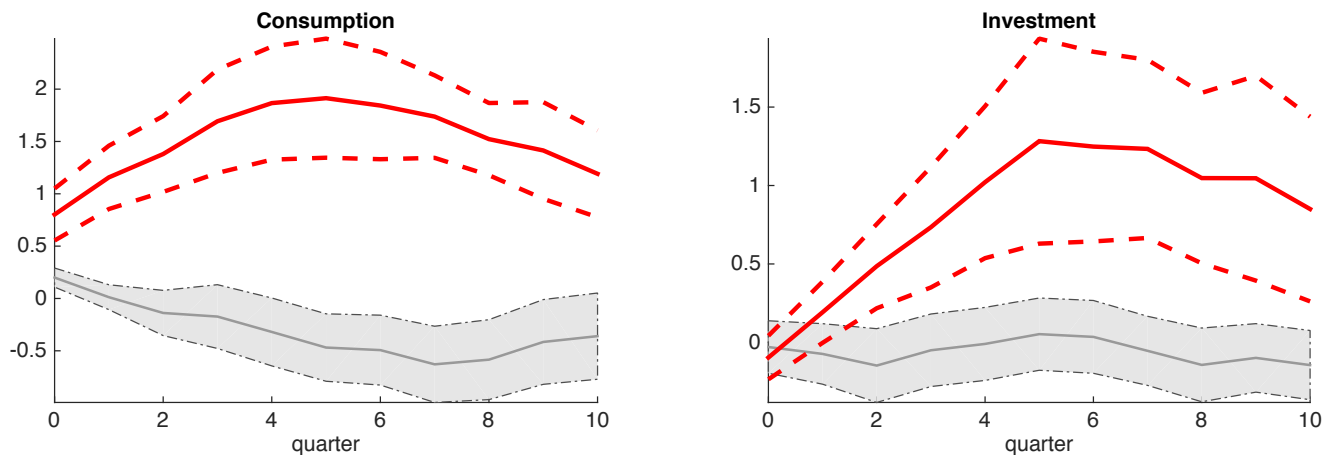

Notes: This figure plots the cumulative multipliers of private consumption and investment in the normal period and in the ZLB period. The borders around point estimates are one standard deviation error bounds. 
Figure 9: Unemployment Multiplier

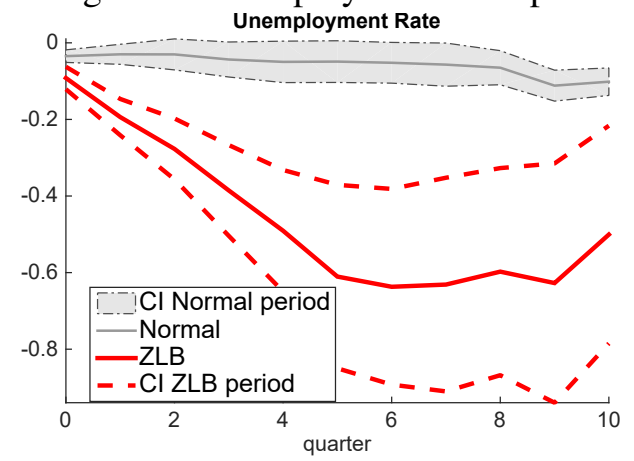

Notes: This figure plots the cumulative multipliers of unemployment rate in the normal period and in the ZLB period. The borders around point estimates are one-standard-deviation error bounds. 
Figure 10: Inflation, Inflation Expectations and Nominal Interest Rates
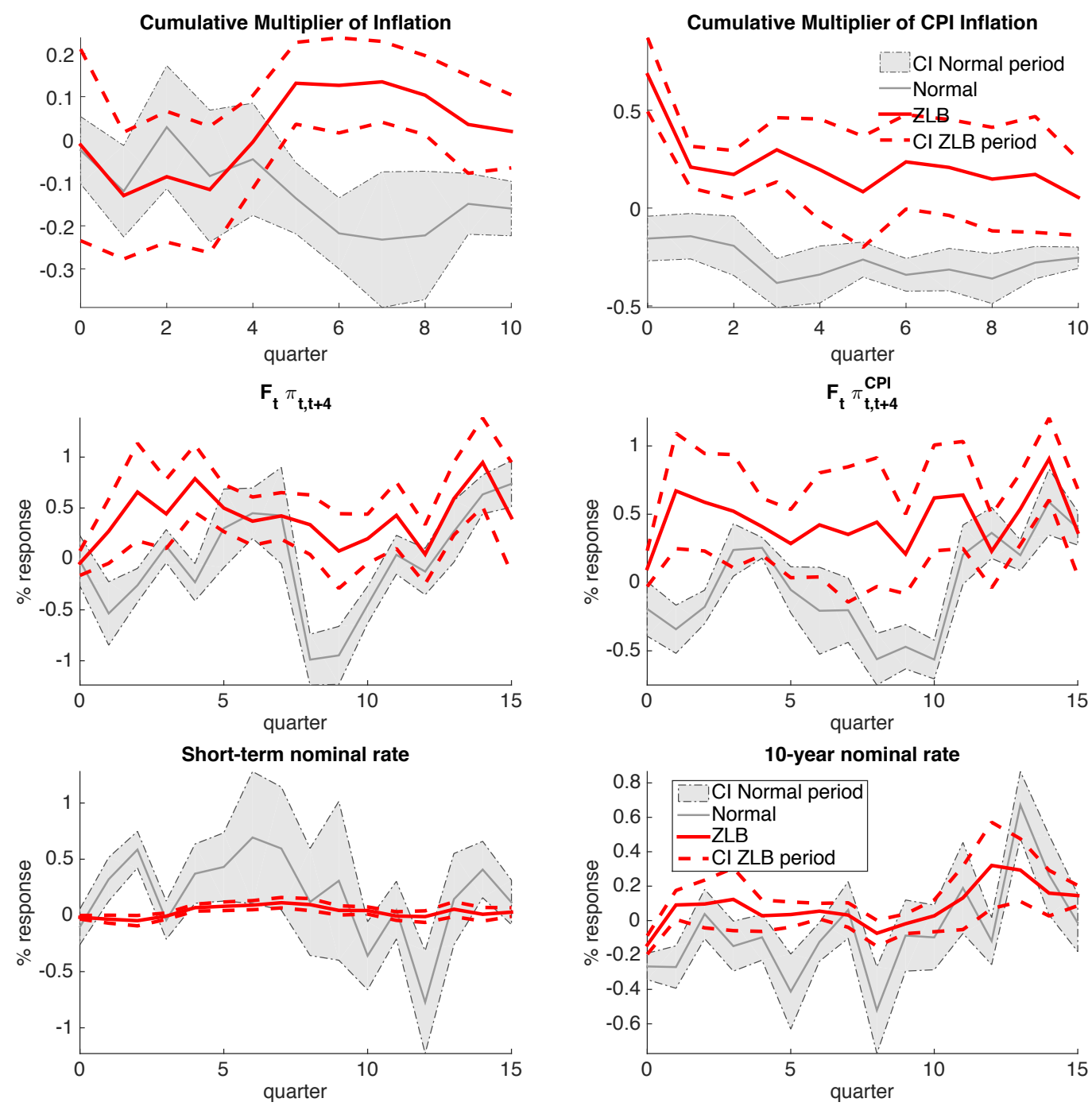

Notes: The first row of the figure plots the cumulative multipliers of inflation, the second row plots the impulse responses of one-year inflation expectations for the GDP deflator and CPI to an increase in government spending by 1 percent of output in normal and ZLB periods. $F_{t} \pi_{t, t+4}$ denotes the annual GDP deflator inflation expectation, while $F_{t} \pi_{t, t+4}^{C P I}$ is the annual CPI inflation expectation. The last row plots the impulse responses of the short-term interest rate set by the Bank of Japan, and the 10-year government bond yield. The borders around point estimates are one-standard-deviation error bounds. 
Figure 11: Output Multiplier during Recessions and Expansions
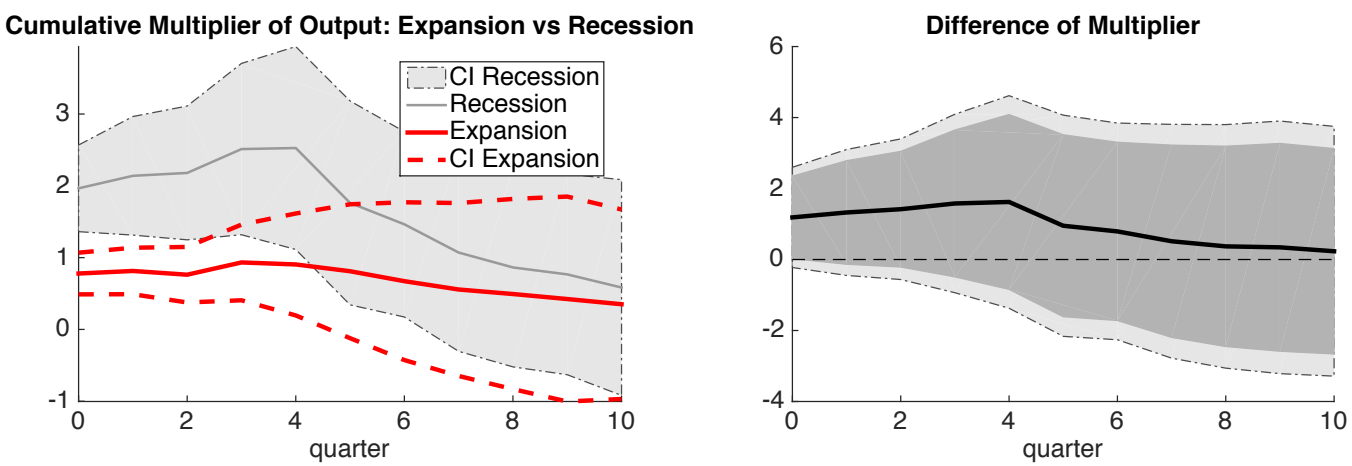

Notes: The left figure plots the output multipliers in recession and in expansion using Japanese data between 1980Q1 and 2014Q1; recessions are defined by the Japanese Cabinet Office. The borders around point estimates on the left figure are one-standard-deviation error bounds. The figure on the right shows the difference in the output multipliers in recessions and in expansions; the 90 percent confidence interval is shown in dark grey and the one-standard-deviation confidence interval is shown in light grey.

Figure 12: Unemployment Rate in Japan

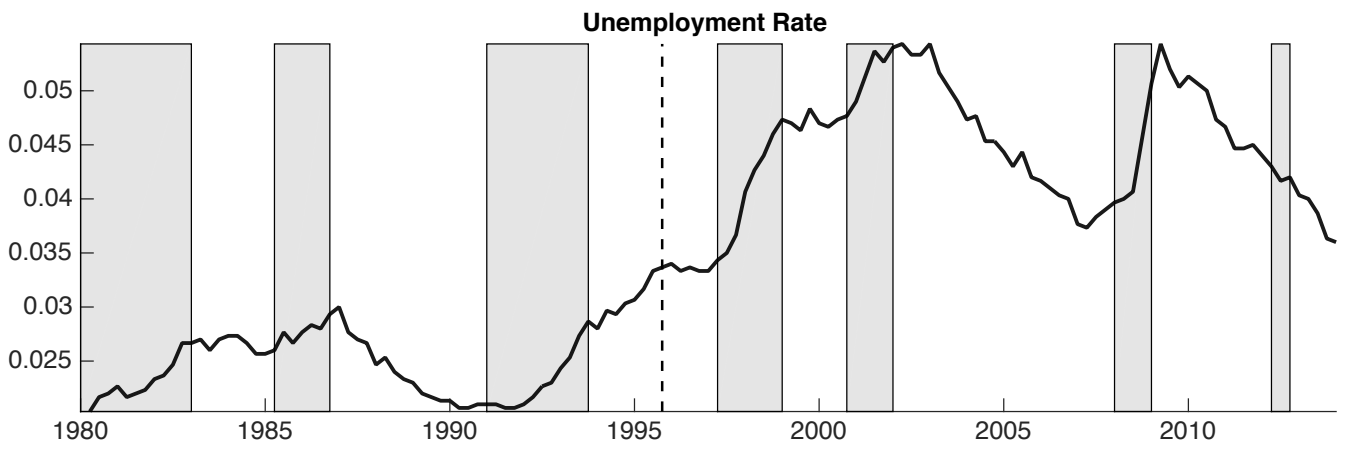

Notes: The shaded areas are Cabinet Office recession dates.

Figure 13: Labor Market Tightness in Japan

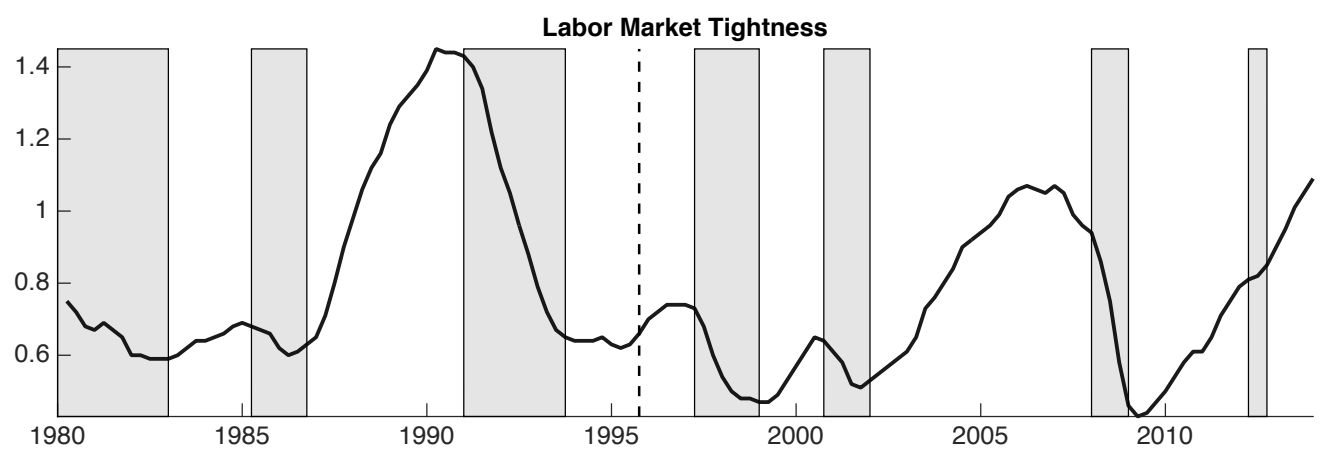

Notes: Labor market tightness is defined as the ratio of job openings to applicants. The shaded areas are Cabinet Office recession dates. 
Figure 14: Average Tax Rate Multiplier

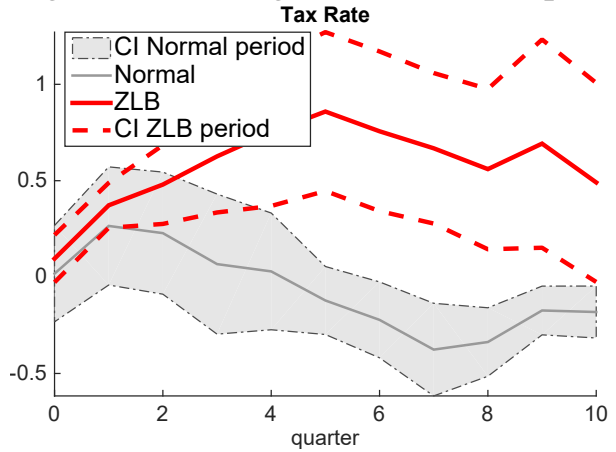

Notes: This figure plots the cumulative multipliers of the average tax rate in the normal period and in the ZLB period. The borders around point estimates are one-standard-deviation error bounds.

Figure 15: Impulse Responses of Components of Government Spending IR of GI to G Shock
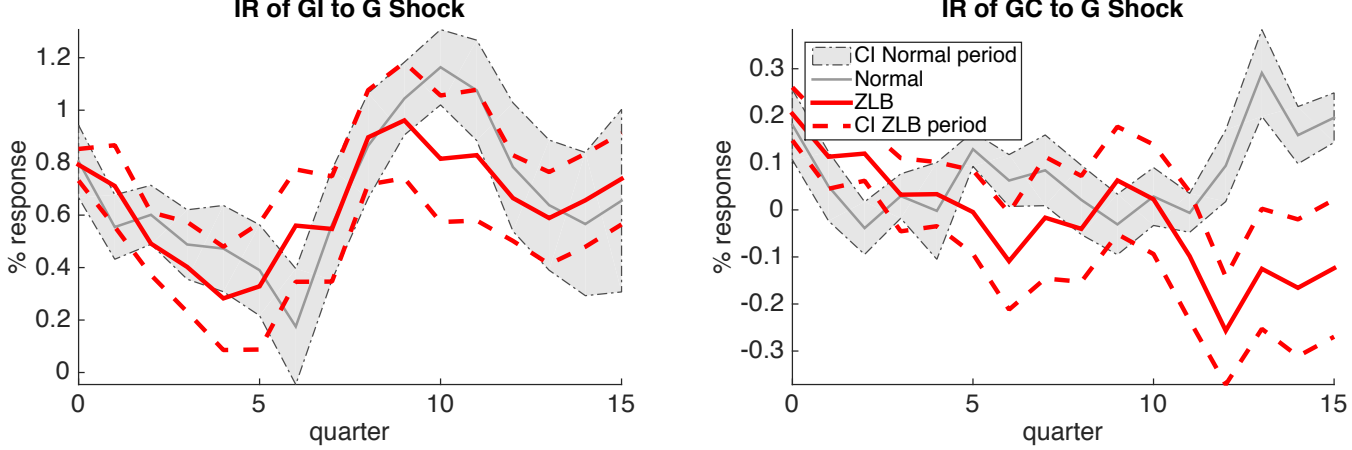

Notes: This figure plots the responses of government investment (left panel) and government consumption (right panel) to an increase in government spending by 1 percent of output. The responses for both government investment and consumption are measured as a percentage of output. The borders around point estimates are one-standard-deviation error bounds. 


\section{Data Appendix}

1. Output, consumption, investment, government spending, tax revenue, net exports, and GDP deflator are from the National Accounts of Japan published on the Cabinet Office website:

- http://www.esri.cao.go.jp/index-e.html (English)

- http://www.esri.cao.go.jp/index.html (Japanese)

Adjusted Government Spending: After 1980, total government consumption includes both transfers (e.g., payment to households for medical services) and consumption (e.g., payment for textbooks). Therefore, we construct the "adjusted government consumption" by excluding transfers from total government consumption from 1980. The sum of "adjusted government consumption" and public investment is about 18 percent of GDP on average. Prior to 1980, Japan adopted the 1968 System of National Accounts, which has a different definition of government consumption. Our adjusted government consumption series is similar to the data on government spending prior to 1980. Japan also has data for "actual final" government consumption after 1980. The definition of this series is the narrowest and accounts for less than 8 percent of output, so the sum of "actual final government consumption" and public investment is about 14 percent of GDP. We note that the estimates using actual final government spending or the unadjusted measure of government consumption are similar to the baseline results.

2. Forecasts of government spending, output and inflation are from the Japan Center for Economic Research:

- http://www.jcer.or.jp/eng/

The JCER data also contain the initial release and up to seven subsequent revisions of realized data. The periods with three forecasts a year are 1972 to 1995,1999 to 2002, and 2004 to 2006. We construct the one-quarter-ahead forecast of the four-quarters growth rate of government spending using real-time data; that is, forecasters do not have the final release of government spending in $t-4$ when making their forecast at time $t-1$.

3. Unemployment rate, labor market tightness, population, and CPI are from Statistics Japan:

- http://www.stat.go.jp/english/data/index.htm (English)

- http://www.stat.go.jp/data/index.htm (Japanese). 
The statistics website can be accessed through http://www.e-stat.go.jp/SG1/estat/ eStat TopportalE.do (English).

4. Nominal interest rates are from the Bank of Japan:

- http://www.stat-search.boj.or.jp/index_en.html (English)

- http://www.stat-search.boj.or.jp/index.html (Japanese)

5. The real effective exchange rate is from the IMF International Financial Statistics database:

- http://www.imf.org/en/Data

6. The government budget outlook, government spending forecast, leading indicators, public construction orders, public work orders, and government budget (initial and final) are from the Japanese NIKKEI NEEDS database:

- http://www.nikkei.co.jp/needs/(Japanese)

7. The OECD and the IMF government spending forecasts are similar to those used in Auerbach and Gorodnichenko (2012b) and were obtained from the authors.

8. The construction sector stock price index is from Haver Analytics.

9. The fiscal packages and supplementary budget were collected from newspaper reports.

10. The Cabinet Office recession dates:

-http://www.esri.cao.go.jp/jp/stat/di/150724hiduke.html (Japanese)

The recession peaks and troughs computation resembles the process of the National Bureau of Economic Research in the United States. 


\section{For Online Publication}

\section{A Robustness}

This section shows that our baseline results about the output multiplier, reported in Section 4.2, are robust to various regression specifications and definitions of variables.

\section{A.1 Additional Predictors of Future Government Spending}

In Section 4.3, we illustrated that it is important to use forecast data to compute the multipliers. We investigate here whether our results are robust to adding more predictive variables to the set of controls in equation (1).

Other JCER Forecasts. We add several additional variables from the JCER database. First, we add the government spending component of the fiscal packages approved by the Japanese government to equation (1). The Japanese government implements fiscal packages from time to time. These packages often contain several measures such as tax cuts, spending, and special transfers. We use the spending component of these packages when these fiscal packages are passed. We also use the information from the supplementary budget for the central government, which are additional budget items approved during a fiscal year. Figure A3 plots these data for the supplementary budget and fiscal packages as a percentage of GDP. The estimated multipliers, when these data are added as controls, are similar to the baseline.

Second, we add a one-year-ahead forecast of the annual government spending growth rate, formally, $F_{t}\left(\ln G_{t+4}-\ln G_{t}\right)$, to equation (1) to control for the possibility that agents know the amount of annual spending but do not know the exact timing. Third, we add one- to four-quarters-ahead forecasts of the quarterly government spending growth rate. Fourth, we include the one-quarter-ahead forecast of output as a variable that can summarize the expected future state of the economy. Fifth, we include the one-year-ahead forecast of the annual output growth rate. Because expected government spending can potentially react to expected changes in output, it may be important to control for expected output.

We report in Table A1 and Figure A4 the estimated multipliers when each of these variables is added one-by-one to equation (1). The point estimates of the output multipliers in both the normal and ZLB periods estimated with additional control variables are close to those in the baseline. The one-standard-deviation confidence intervals for the multipliers in the normal period do not overlap with those in the ZLB periods in most cases. Overall, these results suggest that the JCER forecast of future government spending used 
in our baseline estimation contains much of the information available in the additional variables discussed here. These results also provide more evidence that the output multiplier in the ZLB period is substantially different from that in the normal period.

Other Forecast Sources. We add other forecast sources into our estimation of unexpected government spending shocks. In particular, the OECD Economic Outlook has released annual forecasts for government spending in May and November every year since 1983. The Japanese Cabinet Office's Economic Outlook database contains annual government spending forecast published in December from 1980. The quarterly IMF forecast publishes government spending forecast from 2003. In Figure A2, we plot the actual cumulative growth rate of government spending along with its one-quarter-ahead forecasts from the JCER, the OECD, and the Japanese Cabinet Office's Economic Outlook. This plot suggests that the JCER and the OECD forecasts track the actual government spending well before 2000 but less so after 2000.

We re-estimate equation (1) to include all of the available one-quarter-ahead forecasts of government spending from these sources and compute the multipliers for different horizons in Table A1. The multipliers in the normal period estimated with additional data are similar to those in the baseline. Although the estimates for the multipliers in the ZLB period are slightly higher than the baseline, the difference is small. The differences between the multipliers in the ZLB period and in the normal period are significant at shorter horizons. Overall, these results are in line with the baseline estimation.

Other Macroeconomic Predictors. We add several other macroeconomic variables in equation (1). First, we add four lags of contracted public work orders, orders received for public construction, and the excess returns of construction sector stock prices to control for expected government investment. Second, we consider variables that can include information on the state of the economy and the fiscal stance, such as real exchange rates and the index of leading indicators. The results remain similar to the baseline estimates. For example, in Figure A5, we report the estimates of cumulative multipliers of output in the specification with orders received for public construction and contracted public work orders.

\section{A.2 Variations of the Baseline Specification}

We show that the baseline results are robust to changes in the baseline specification.

First, we estimate a version of specification (2) with a quadratic trend since time series estimates can be sensitive to trends. Table A1 displays the output multipliers in this case. We find that the multipliers estimated with a trend are similar to those in the baseline, although the output multiplier estimated with a 
trend in the normal time is somewhat larger at longer horizons than in the baseline.

Second, we perform an alternative transformation of government spending and output by dividing them by potential output to calculate the multipliers. The motivation for this approach is as follows: In our baseline estimation, we normalize government spending changes by past GDP. A potential problem with this transformation is that fluctuations in output can bias the estimated multiplier. Instead, we estimate equation (3) for $\left(Y_{t+h}-Y_{t-1}\right) / \bar{Y}_{t-1}$ and $\left(G_{t+h}-G_{t-1}\right) / \bar{Y}_{t-1}$, where $\bar{Y}_{t}$ is potential output, computed using the Hodrick-Prescott (HP) filter with the smoothing parameter of 1600. The multipliers estimated in this case, reported in Table A1, are close to our baseline.

Third, one potential concern with our estimation is that we use the residuals $\widehat{\varepsilon}_{t}$ of equation (1) to proxy for shock $k_{t}$ without taking into account the uncertainty of the estimates. We address this concern and implement a one-step estimation of the effects of unexpected government spending on output. Formally, we estimate the following version of equation (3):

$$
\sum_{j=0}^{h} x_{t+j}=\alpha_{h}^{x}+M_{h} \sum_{j=0}^{h} \frac{G_{t+j}-G_{t-1}}{Y_{t-1}}+\gamma_{h}^{x} F_{t-1} \Delta \ln G_{t}+\psi_{h}^{x}(L) y_{t-1}+\varepsilon_{t+h}^{x}, \quad \text { for } h=0,1,2, \ldots
$$

where we instrument $\sum_{j=0}^{h} \frac{G_{t+j}-G_{t-1}}{Y_{t-1}}$ with the current growth rate of government spending because the regression includes both forecast and lags of control variables. This approach has the same interpretation as our two-step procedure. The results obtained from this estimation are shown in Table A1. The multipliers are virtually identical to our baseline estimates. The standard errors of the one-step and the baseline estimations are also similar.

Fourth, we estimate the output multiplier from a five-variable structural vector autoregression (SVAR). The five variables are government spending forecast, government spending, tax revenue, output growth, and the unemployment rate. As in the baseline, we include four lags of these variables in the SVAR. The SVAR results are close to the baseline estimation using the local projection method. Figure A7 compares the impulse responses of government spending and output to a government spending shock in the normal and ZLB periods obtained using the SVAR and the local projection method. The differences in the multipliers are statistically significant as in the baseline estimation.

Fifth, we estimate specification (3) by adding lags of extracted government spending shocks to alleviate the concern that our shocks are serially correlated. The results are close to the benchmark and plotted in Figure A8.

Finally, we estimate a fifteen-year rolling-window regression version of our baseline specification between 1967Q1 and 2014Q1. This allows us to check if there is evidence that the change in output multiplier 
occurred around the start of the ZLB period. Figure A9 plots the multiplier at different horizons. The multiplier is time-varying. Between 1967 and 1984, the cumulative output multiplier is about 1.2 on impact and increases to about 3 at a two-year horizon. This result shows that the multiplier can be larger than one during the 1960s and 1970s when the Japanese economy was under the fixed exchange rate regime. After the collapse of the fixed exchange rate regime, the multiplier is below unity for all years up to 1997 . This result is consistent with the finding in Ilzetzki, Mendoza, and Végh (2013) that the multiplier is larger in the fixed exchange rate regime than in the flexible exchange rate regime. The multiplier becomes higher than unity starting in 1995. This tendency is similar across all horizons. Overall, the rolling regression results are consistent with our baseline estimates and suggests that the multiplier is larger in the ZLB period than in the period before 1995 .

\section{A.3 Alternative Inflation Measures}

In the main text, we reported results for the GDP deflator and CPI. In addition, we report the responses of core CPI inflation here. Because both total CPI and core CPI were affected by the consumption tax hikes in 1989 and 1997, we also consider the responses of inflation adjusted for these consumption tax changes following Hayashi and Koeda (2014): We adjust the annual inflation rates from April 1989 to March 1990 and from April 1997 to March 1998 for the consumption tax increases, then recover the CPI level consistent with the adjusted annual inflation rates. The responses of inflation calculated from these series are plotted in Figure A11. The inflation responses using either tax-adjusted inflation or core CPI resemble the baseline. The tax-adjusted CPI inflation responses are positive for the first five quarters in the ZLB period. When food and energy are excluded, core CPI inflation also increases significantly in the ZLB period on impact. 
Table A1: Output Multiplier: Robustness

\begin{tabular}{|c|c|c|c|c|c|}
\hline \multicolumn{3}{|c|}{ Normal } & \multicolumn{3}{|c|}{ ZLB } \\
\hline On impact & 4 quarter & 8 quarter & On impact & 4 quarter & 8 quarter \\
\hline \multicolumn{6}{|l|}{ The baseline } \\
\hline $\begin{array}{c}0.61 \\
(0.23)\end{array}$ & $\begin{array}{c}0.12 \\
(0.58)\end{array}$ & $\begin{array}{l}-0.56 \\
(0.34)\end{array}$ & $\begin{array}{c}1.54 \\
(0.43)\end{array}$ & $\begin{array}{c}2.67 \\
(1.11)\end{array}$ & $\begin{array}{l}1.70 \\
(0.94)\end{array}$ \\
\hline \multicolumn{6}{|c|}{ No forecast data } \\
\hline $\begin{array}{c}0.38 \\
(0.18)\end{array}$ & $\begin{array}{l}-0.19 \\
(0.44)\end{array}$ & $\begin{array}{l}-0.49 \\
(0.38)\end{array}$ & $\begin{array}{l}1.49 \\
(0.42)\end{array}$ & $\begin{array}{c}2.43 \\
(1.01)\end{array}$ & $\begin{array}{c}1.53 \\
(0.86)\end{array}$ \\
\hline \multicolumn{6}{|c|}{ Add fiscal packages } \\
\hline $\begin{array}{c}0.75 \\
(0.27)\end{array}$ & $\begin{array}{c}0.29 \\
(0.65)\end{array}$ & $\begin{array}{l}-0.29 \\
(0.35)\end{array}$ & $\begin{array}{l}1.63 \\
(0.47)\end{array}$ & $\begin{array}{c}2.53 \\
(1.09)\end{array}$ & $\begin{array}{l}1.52 \\
(1.06)\end{array}$ \\
\hline \multicolumn{6}{|c|}{ Add one-quarter-ahead GDP forecast } \\
\hline $\begin{array}{c}0.57 \\
(0.23)\end{array}$ & $\begin{array}{c}0.05 \\
(0.56)\end{array}$ & $\begin{array}{l}-0.57 \\
(0.40)\end{array}$ & $\begin{array}{l}1.45 \\
(0.43)\end{array}$ & $\begin{array}{c}2.57 \\
(1.11)\end{array}$ & $\begin{array}{c}1.58 \\
(0.95)\end{array}$ \\
\hline \multicolumn{6}{|c|}{ Add one- to four-quarters-ahead of $G$} \\
\hline $\begin{array}{c}0.54 \\
(0.27)\end{array}$ & $\begin{array}{c}0.29 \\
(0.56)\end{array}$ & $\begin{array}{l}-0.36 \\
(0.37)\end{array}$ & $\begin{array}{c}1.64 \\
(0.45)\end{array}$ & $\begin{array}{c}2.89 \\
(1.29)\end{array}$ & $\begin{array}{c}2.10 \\
(1.08)\end{array}$ \\
\hline \multicolumn{6}{|c|}{ Add four-quarters-ahead annual G } \\
\hline $\begin{array}{c}0.57 \\
(0.22)\end{array}$ & $\begin{array}{l}-0.06 \\
(0.53)\end{array}$ & $\begin{array}{l}-0.72 \\
(0.31)\end{array}$ & $\begin{array}{l}1.66 \\
(0.43)\end{array}$ & $\begin{array}{c}2.72 \\
(1.12)\end{array}$ & $\begin{array}{c}1.80 \\
(1.00)\end{array}$ \\
\hline \multicolumn{6}{|c|}{ Add four-quarters-ahead annual GDP } \\
\hline $\begin{array}{c}0.57 \\
(0.23)\end{array}$ & $\begin{array}{l}-0.16 \\
(0.57)\end{array}$ & $\begin{array}{l}-0.75 \\
(0.30)\end{array}$ & $\begin{array}{c}1.41 \\
(0.43)\end{array}$ & $\begin{array}{c}2.67 \\
(1.27)\end{array}$ & $\begin{array}{c}2.37 \\
(1.33)\end{array}$ \\
\hline \multicolumn{6}{|c|}{ Add OECD, IMF and Government Outlook forecasts } \\
\hline $\begin{array}{c}0.58 \\
(0.21)\end{array}$ & $\begin{array}{c}0.19 \\
(0.54)\end{array}$ & $\begin{array}{l}-0.41 \\
(0.30)\end{array}$ & $\begin{array}{c}1.66 \\
(0.60)\end{array}$ & $\begin{array}{c}3.42 \\
(1.81)\end{array}$ & $\begin{array}{c}2.47 \\
(1.35)\end{array}$ \\
\hline \multicolumn{6}{|c|}{ Quadratic trend } \\
\hline $\begin{array}{c}0.69 \\
(0.29)\end{array}$ & $\begin{array}{c}0.52 \\
(0.54)\end{array}$ & $\begin{array}{c}0.77 \\
(0.73)\end{array}$ & $\begin{array}{l}1.89 \\
(0.52)\end{array}$ & $\begin{array}{l}5.13 \\
(2.52)\end{array}$ & $\begin{array}{c}5.74 \\
(3.71)\end{array}$ \\
\hline \multicolumn{6}{|c|}{ Normalized by potential output } \\
\hline $\begin{array}{c}0.61 \\
(0.23)\end{array}$ & $\begin{array}{c}0.11 \\
(0.57)\end{array}$ & $\begin{array}{c}-0.58 \\
(0.32)\end{array}$ & $\begin{array}{l}1.54 \\
(0.43)\end{array}$ & $\begin{array}{l}2.68 \\
(1.12)\end{array}$ & $\begin{array}{c}1.66 \\
(0.96)\end{array}$ \\
\hline \multicolumn{6}{|c|}{ One-step estimation } \\
\hline $\begin{array}{c}0.61 \\
(0.23)\end{array}$ & $\begin{array}{c}0.12 \\
(0.52)\end{array}$ & $\begin{array}{l}-0.56 \\
(0.33)\end{array}$ & $\begin{array}{c}1.54 \\
(0.41)\end{array}$ & $\begin{array}{c}2.58 \\
(1.06)\end{array}$ & $\begin{array}{c}1.54 \\
(0.83)\end{array}$ \\
\hline
\end{tabular}

Notes: Panel "The baseline" reproduces results from Table 1. Panel "No forecast data" reports the estimates without controlling for expectations data. Panel "Add fiscal packages" are the results with the fiscal packages added in the baseline estimation. "Add one-quarter-ahead output forecast" reports the results when we add a one-quarter-ahead forecast of the output growth rate to identify spending shocks. Panel "Add one- to four-quarters-ahead of G" reports results when forecasts of government spending from horizons one to four quarters ahead are included. Panels "Add four-quarters-ahead annual G" and "Add four-quarters-ahead annual GDP" report the cases when we add four-quarters-ahead forecast of annual spending growth rate and GDP growth rate into the estimation, respectively. Panel "Add OECD, IMF and Government Outlook" reports results with additional one-quarter-ahead forecasts from different sources into the estimation. Panel "Quadratic trend" shows the results when the time trend is added in the baseline. Panel "Normalized by potential output" reports the estimates when output and government spending changes in the baseline specification are divided by potential output. Panel "One-step estimation" estimates the output multiplier in one regression by adding a one-quarter-ahead forecast of government spending to the control variables. All numbers in parentheses are the standard errors. 
Table A2: Multipliers of Inflation and Interest rates

\begin{tabular}{|c|c|c|c|}
\hline & On impact & Horizon 4 & Horizon 8 \\
\hline \multicolumn{4}{|c|}{ GDP deflator inflation } \\
\hline Normal & $\begin{array}{c}-0.02 \\
(0.08)\end{array}$ & $\begin{array}{l}-0.05 \\
(0.13)\end{array}$ & $\begin{array}{l}-0.22 \\
(0.15)\end{array}$ \\
\hline ZLB & $\begin{array}{c}-0.01 \\
(0.22)\end{array}$ & $\begin{array}{l}-0.01 \\
(0.11)\end{array}$ & $\begin{array}{c}0.10 \\
(0.09)\end{array}$ \\
\hline \multicolumn{4}{|c|}{ CPI inflation } \\
\hline Normal & $\begin{array}{l}-0.16 \\
(0.11)\end{array}$ & $\begin{array}{l}-0.34 \\
(0.15)\end{array}$ & $\begin{array}{l}-0.36 \\
(0.13)\end{array}$ \\
\hline ZLB & $\begin{array}{c}0.68 \\
(0.19)\end{array}$ & $\begin{array}{c}0.20 \\
(0.26)\end{array}$ & $\begin{array}{c}0.15 \\
(0.26)\end{array}$ \\
\hline \multicolumn{4}{|c|}{ GDP deflator inflation expectation } \\
\hline Normal & $\begin{array}{c}-0.02 \\
(0.25)\end{array}$ & $\begin{array}{l}-0.23 \\
(0.18)\end{array}$ & $\begin{array}{l}-0.99 \\
(0.25)\end{array}$ \\
\hline ZLB & $\begin{array}{l}-0.04 \\
(0.12)\end{array}$ & $\begin{array}{c}0.79 \\
(0.33)\end{array}$ & $\begin{array}{c}0.37 \\
(0.29)\end{array}$ \\
\hline \multicolumn{4}{|c|}{ CPI inflation expectation } \\
\hline Normal & $\begin{array}{c}-0.19 \\
(0.20)\end{array}$ & $\begin{array}{l}(0.25) \\
(0.08)\end{array}$ & $\begin{array}{l}-0.21 \\
(0.19)\end{array}$ \\
\hline ZLB & $\begin{array}{c}0.10 \\
(0.13)\end{array}$ & $\begin{array}{c}0.40 \\
(0.21)\end{array}$ & $\begin{array}{c}0.44 \\
(0.47)\end{array}$ \\
\hline \multicolumn{4}{|c|}{ Short-term interest rate } \\
\hline Normal & $\begin{array}{c}-0.10 \\
(0.16)\end{array}$ & $\begin{array}{c}0.37 \\
(0.26)\end{array}$ & $\begin{array}{c}0.12 \\
(0.59)\end{array}$ \\
\hline ZLB & $\begin{array}{l}-0.02 \\
(0.02)\end{array}$ & $\begin{array}{c}0.07 \\
(0.03)\end{array}$ & $\begin{array}{c}0.10 \\
(0.05)\end{array}$ \\
\hline \multicolumn{4}{|c|}{ Long-term interest rate } \\
\hline Normal & $\begin{array}{c}-0.27 \\
(0,08)\end{array}$ & $\begin{array}{l}-0.10 \\
(0.13)\end{array}$ & $\begin{array}{l}-0.52 \\
(0.25)\end{array}$ \\
\hline ZLB & $\begin{array}{l}-0.14 \\
(0.05)\end{array}$ & $\begin{array}{c}0.03 \\
(0.09)\end{array}$ & $\begin{array}{l}-0.07 \\
(0.08)\end{array}$ \\
\hline
\end{tabular}

Notes: This table reports the multipliers of inflation and inflation expectations, and the impulse responses of short-term and long-term nominal interest rates to an increase in government spending by 1 percent of output. All numbers in parentheses are the standard errors. 
Figure A1: Components of Government Spending in Japan
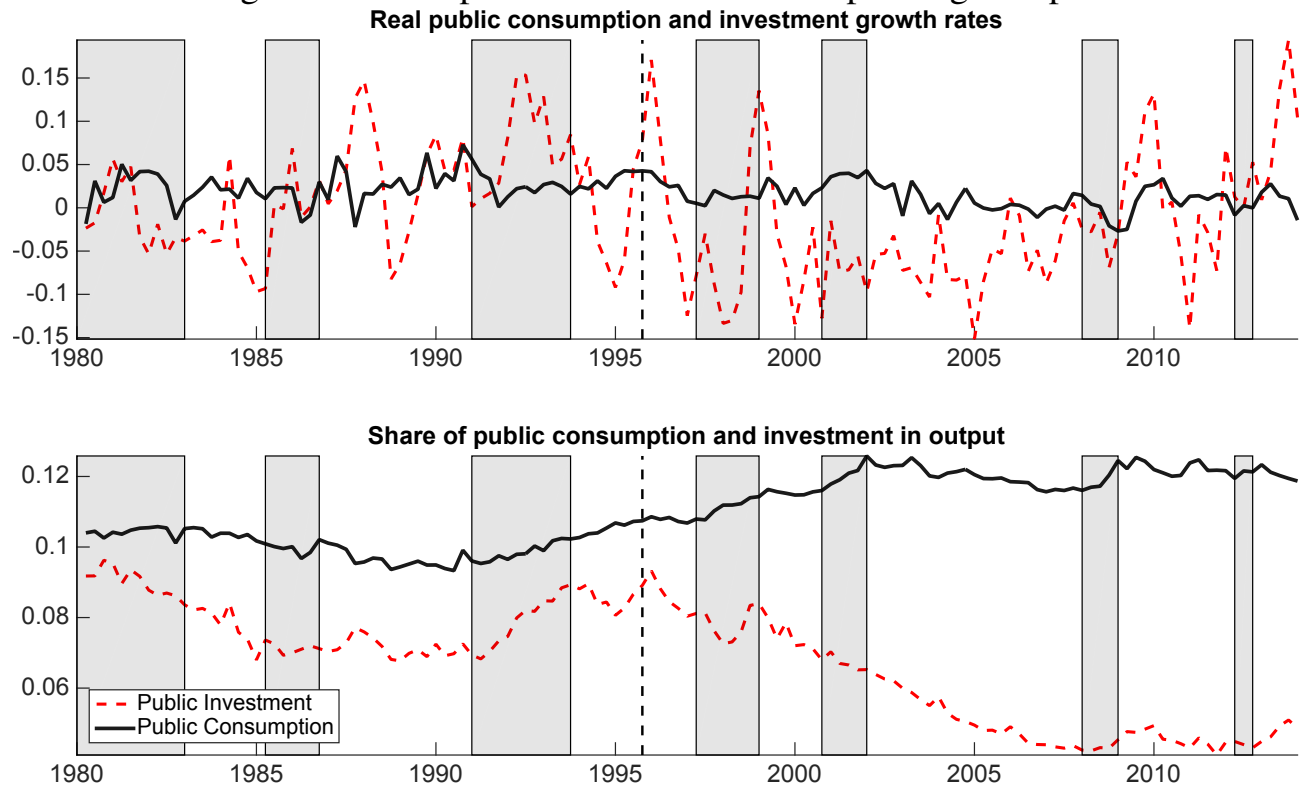

Notes: The shaded areas are Cabinet Office recession dates.

Figure A2: Other Annual Forecasts of Government Spending
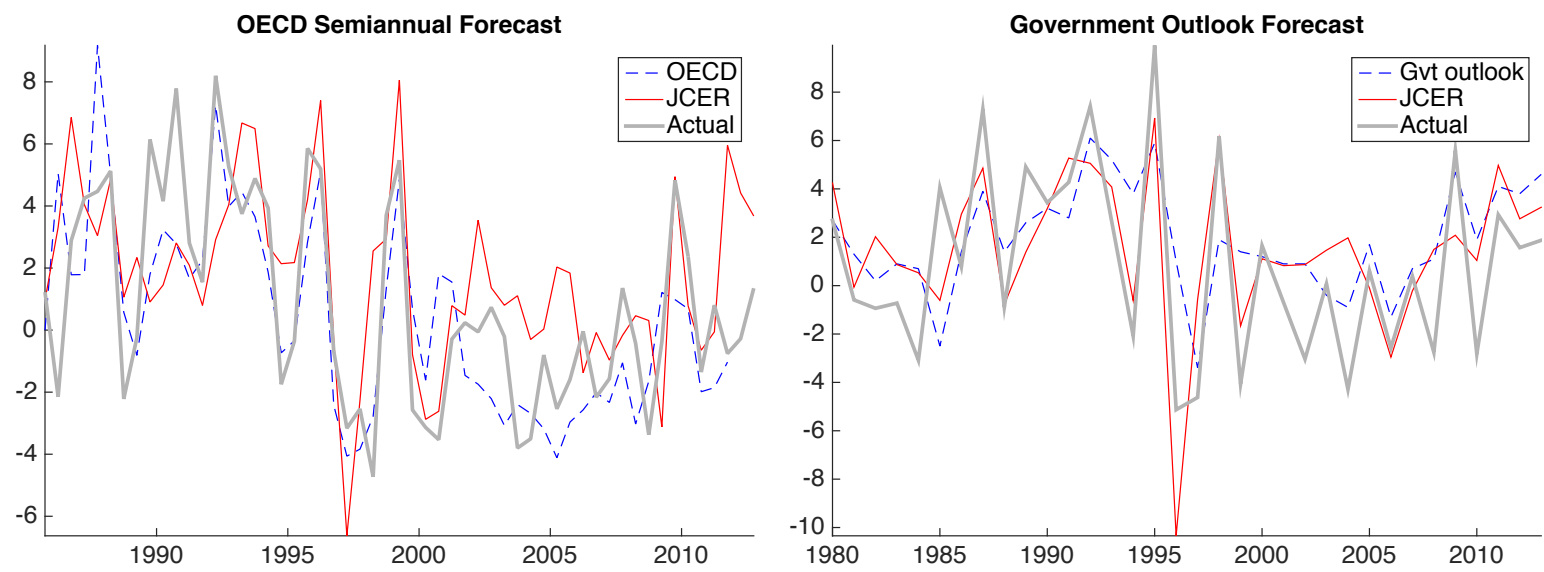

Notes: The figures plot the semiannual forecast of government spending from the OECD (in the left figure), and the annual forecast of government spending from the Japanese Cabinet Office's Economic Outlook (in the right figure) against the same horizon JCER forecast and the actual government spending data. 
Figure A3: Supplementary Budget, Fiscal Packages and Total Government Budget in Japan
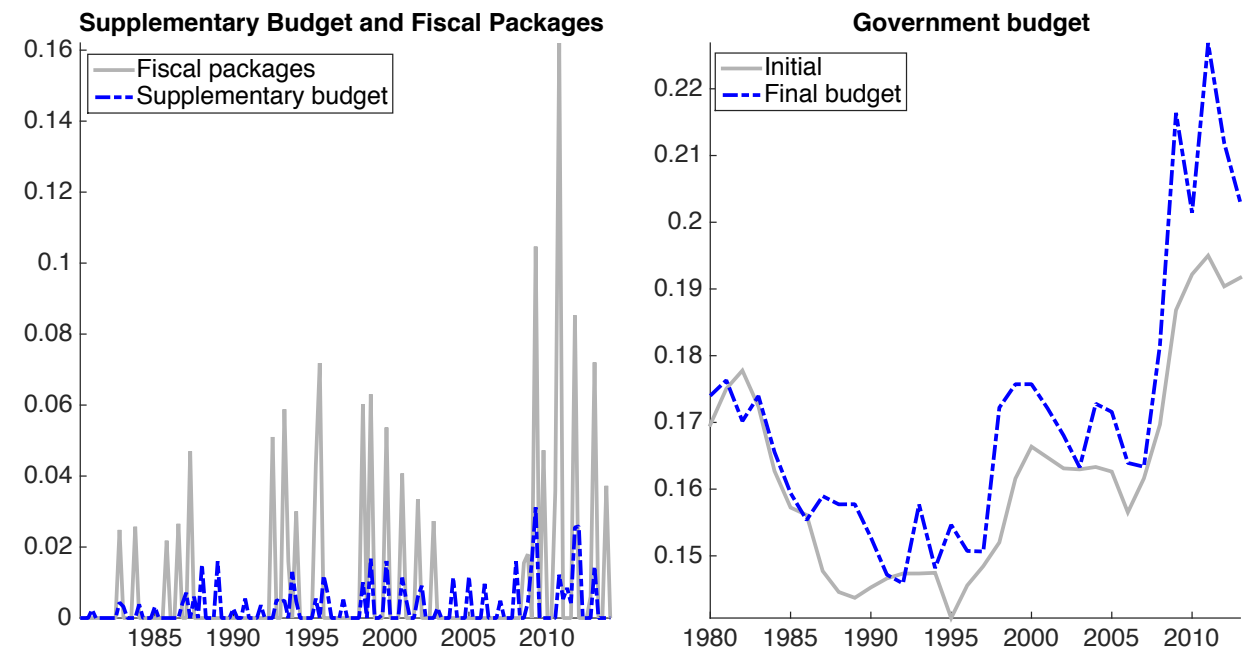

Notes: Supplementary budget for the central government, fiscal packages, and government budgets for the central government are calculated as a ratio of nominal GDP. 
Figure A4: Output Multipliers: Adding Other Sources of Real-time Information

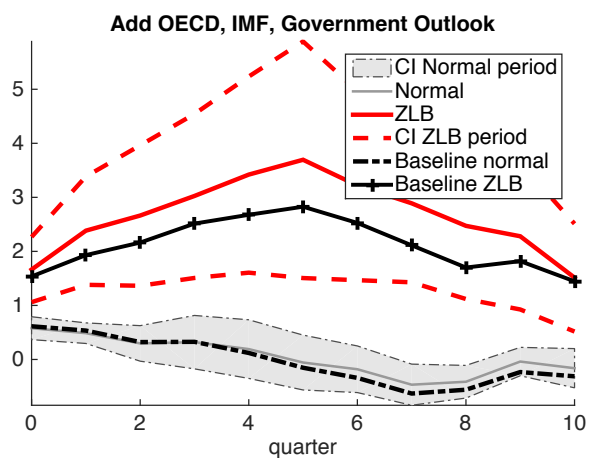

Add One-Quarter-Ahead GDP forecast

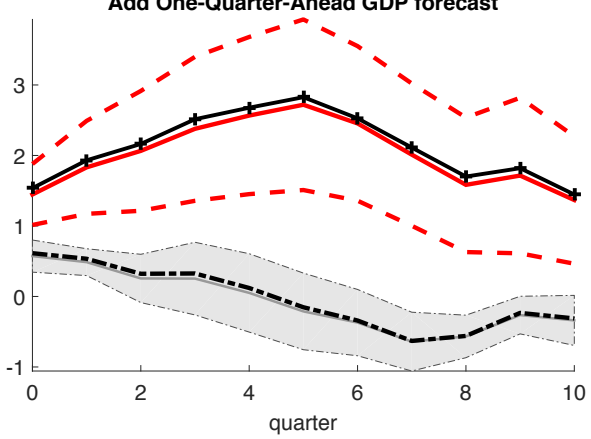

Add Four-quarter ahead annual G

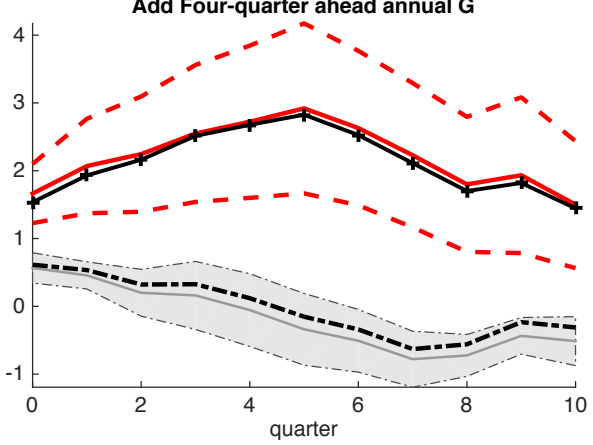

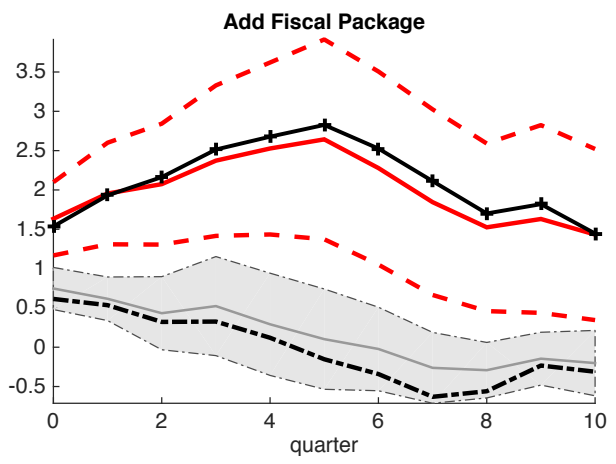

Add Forecast of G horizon up to 4

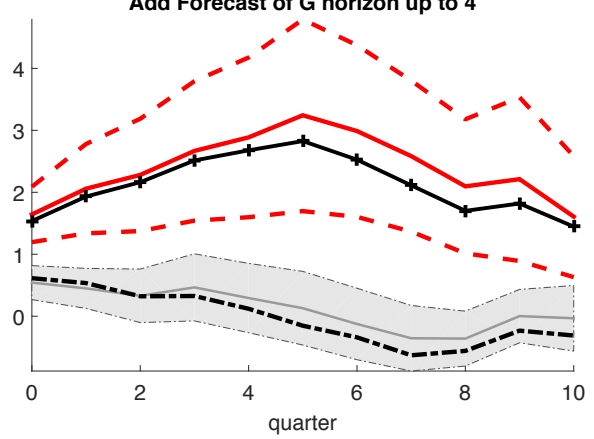

Add Four-quarter ahead annual GDP

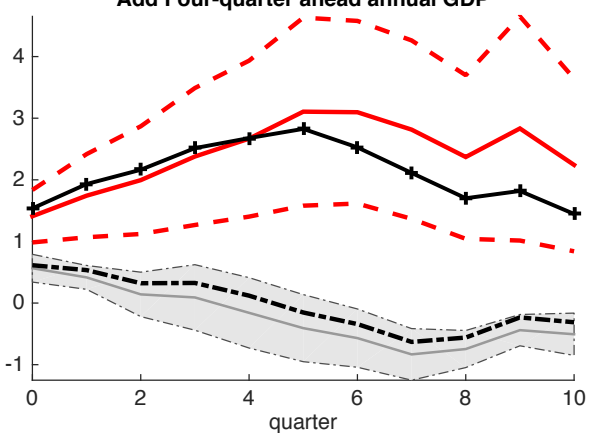

Notes: This figure plots the output multiplier when we add several series to the controls. The black lines are the estimates in the ZLB (with plus signs) and in the normal period (dotted) in the baseline.

Figure A5: Cumulative Output Multipliers: More controls
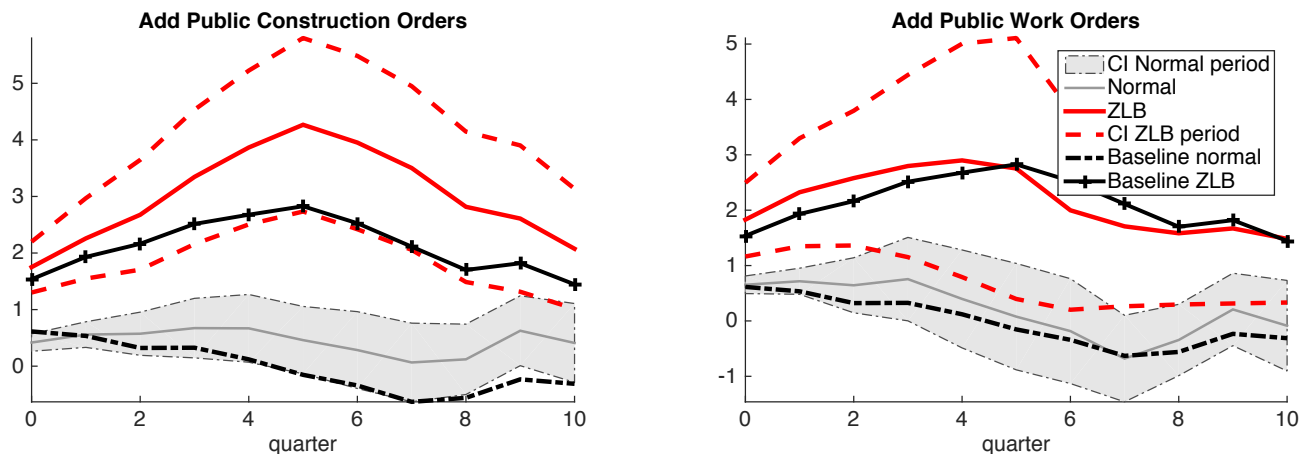

Notes: The figure plots the cumulative output multipliers when we add orders received for public construction (left panel) and contracted public work orders (right panel). 
Figure A6: Predictability of Government Spending Shocks without Controlling for Expectations

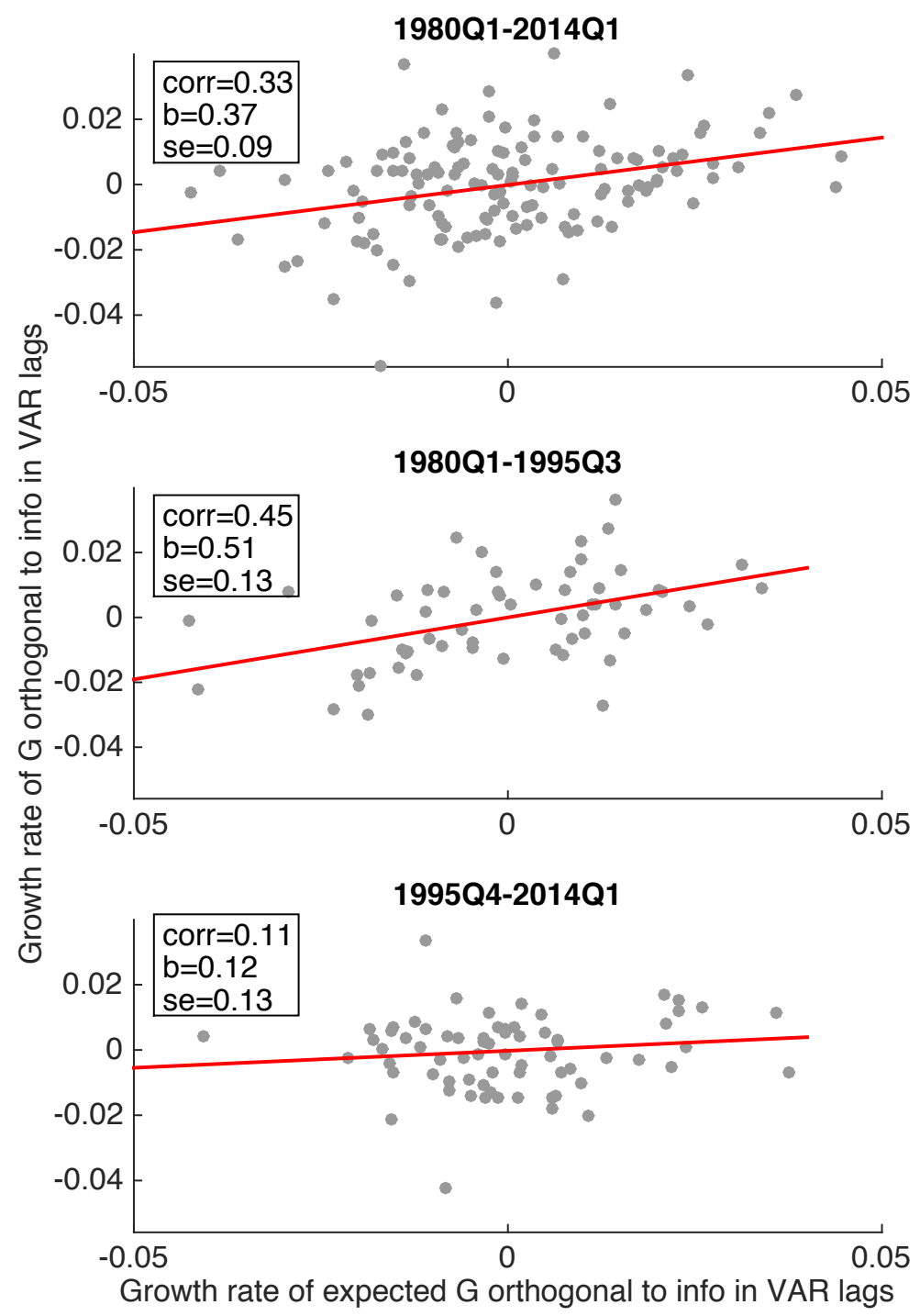

Notes: The figure plots residuals from the projection of the growth rate of government spending predicted in JCER forecasts (horizontal axis) and actual growth rate of government spending (vertical axis) on the information contained in the lags of output, government spending and tax revenues. corr denotes the correlation between the two series, $b$ is the regression coefficient, and se is the standard errors of the regression coefficient. Specifically, we estimate the following specification: $x_{t}=\alpha^{g}+\psi^{g}(L) y_{t-1}+\varepsilon_{t}^{g}$, for two cases. In the first case, the dependent variable $x_{t}$ is the realized government spending growth rate, $\Delta \ln G_{t}$; we obtain the residuals, $\widehat{\varepsilon}_{1, t}^{g}$. In the second case, the dependent variable $x_{t}$ is the one-quarterahead forecast of government spending, $F_{t-1} \Delta \ln G_{t}$; the residuals for this case are $\widehat{\varepsilon}_{2, t}^{g}$. We then calculate the correlation between $\widehat{\varepsilon}_{1, t}^{g}$ and $\widehat{\varepsilon}_{2, t}^{g}$. A non-negative correlation implies that some of the government spending shocks identified without forecast data are predictable. For the entire sample 1980Q1-2014Q1, the correlation between the two residuals is 0.34 and statistically significant, suggesting that there is some forecastability of government spending shocks $\widehat{\varepsilon}_{1, t}^{g}$ identified without forecast data. This correlation is 0.45 in the normal period but only 0.11 for the ZLB period between 1995Q4 and 2014Q1. This result suggests that the changes in government spending are less predictable in the ZLB period than in the normal period. 
Figure A7: SVAR Impulse Responses
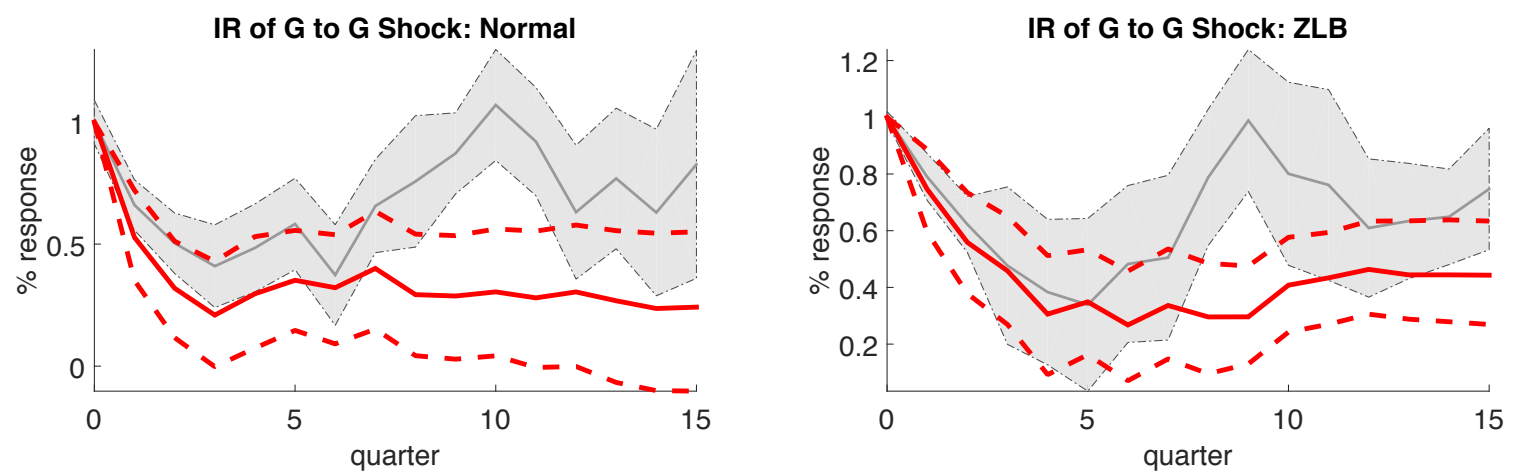

IR of $Y$ to G Shock: Normal
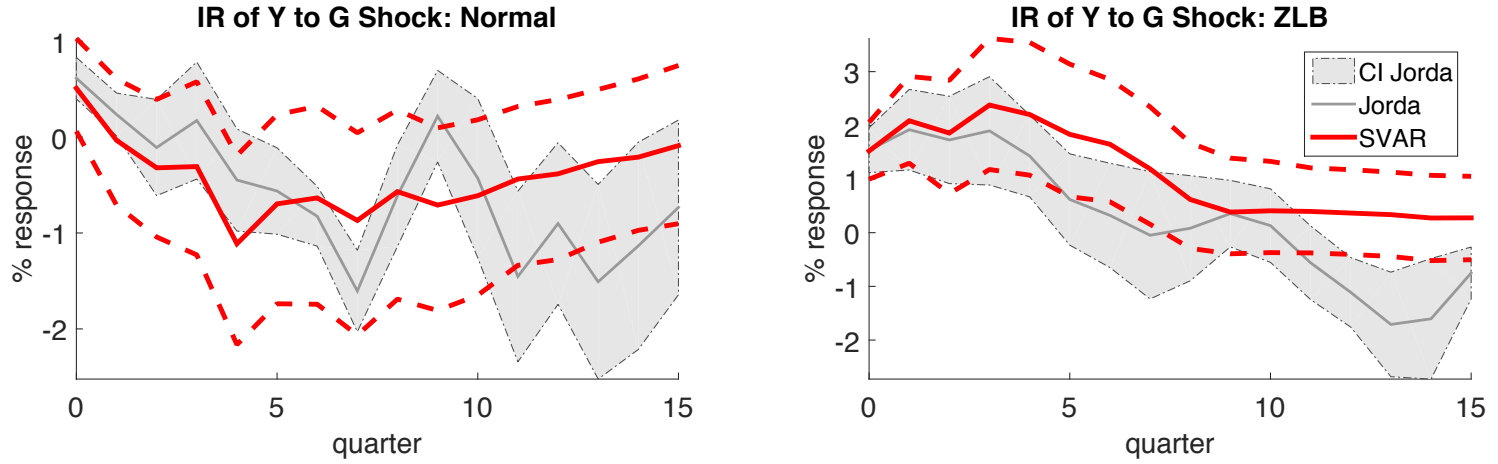

Notes: The figure plots the output and government spending impulse responses to a 1 percent government spending shock in the ZLB period and the normal period estimated from a 5-variable structural vector autoregression.

Figure A8: Output Multiplier With shock ${ }_{t}$ Lags

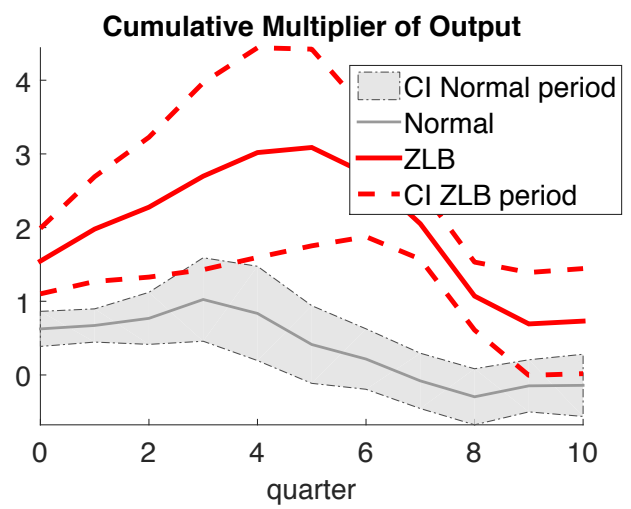

Notes: This figure plots the multiplier of output when we include four lags of shock $k_{t}$ in the estimation. 
Figure A9: Output Multiplier: Rolling Estimation
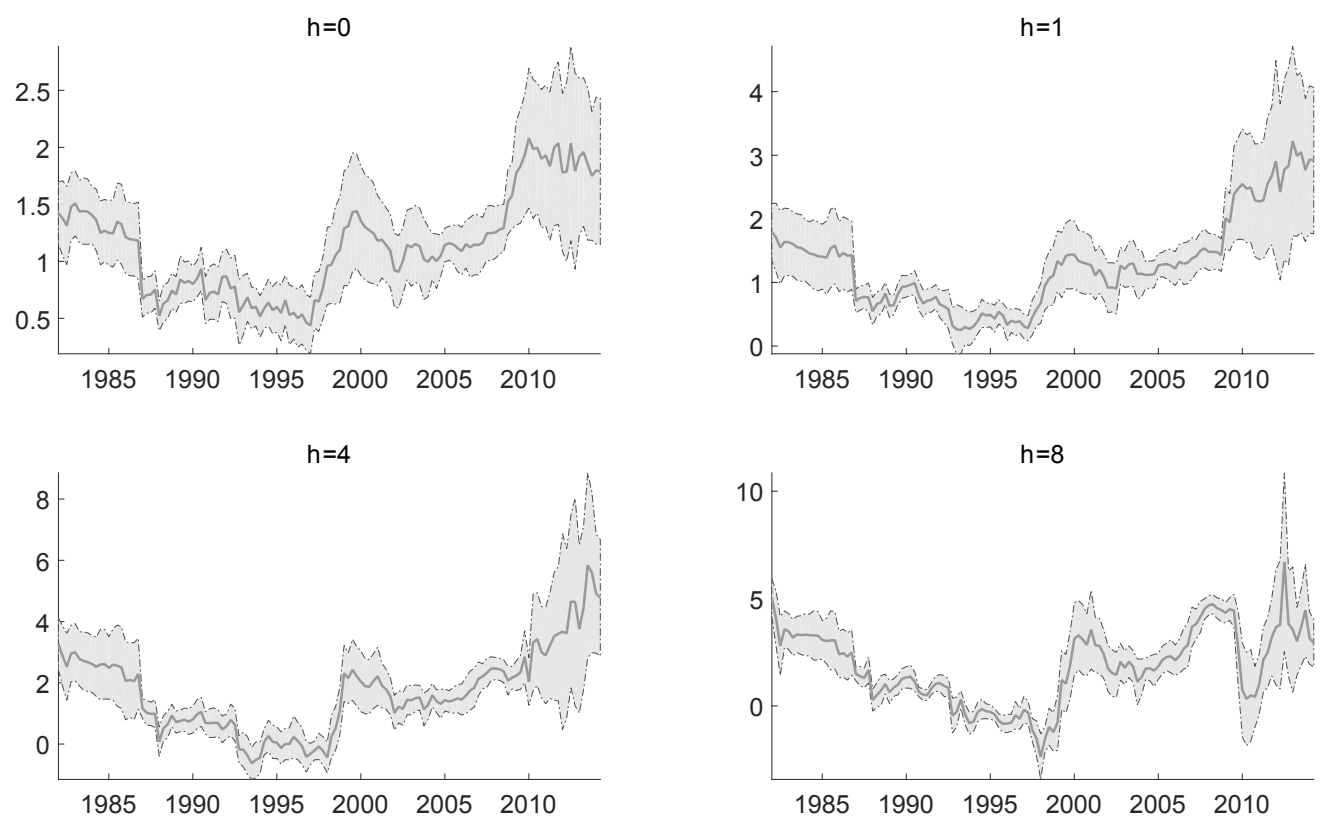

Notes: The year of a reported multiplier corresponds to the last year of the 60-quarter window. For example, a multiplier reported for 1990Q1 is estimated over the period 1975Q1-1990Q1. Each plot corresponds to the output multiplier at a different horizon $h$ (in quarters). The grey areas are one-standard-deviation error bounds.

Figure A10: One-Quarter-Ahead Inflation Expectations Multiplier
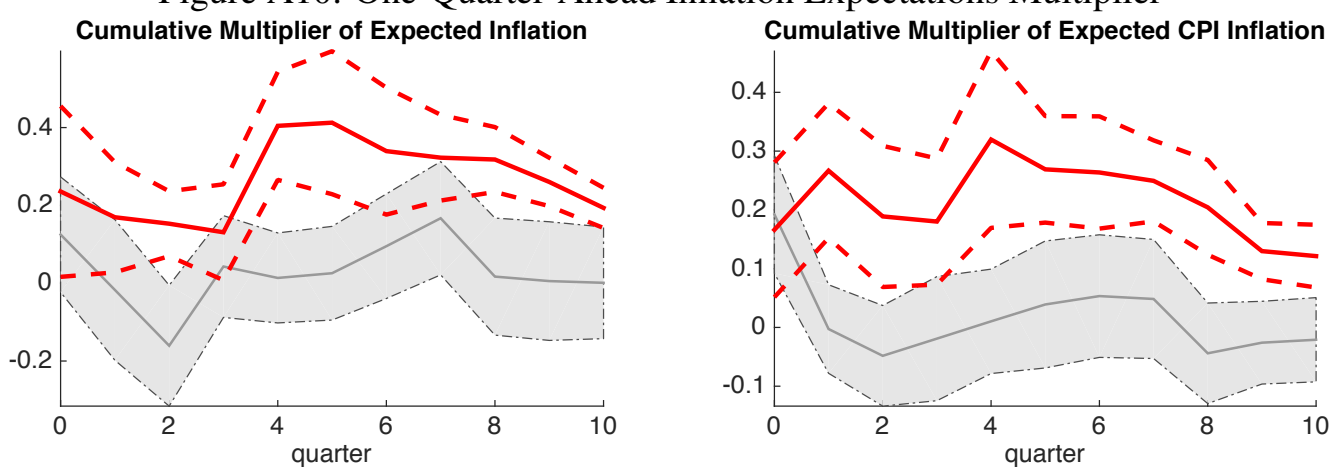

Notes: "One-quarter-ahead inflation expectation" is the inflation expectation from the GDP deflator forecast, $F_{t-1} \pi_{t}$, and "One-quarter-ahead CPI inflation expectation" is the inflation expectation from the CPI forecast, $F_{t-1} \pi_{t}^{C P I}$. 
Figure A11: Different Inflation Data
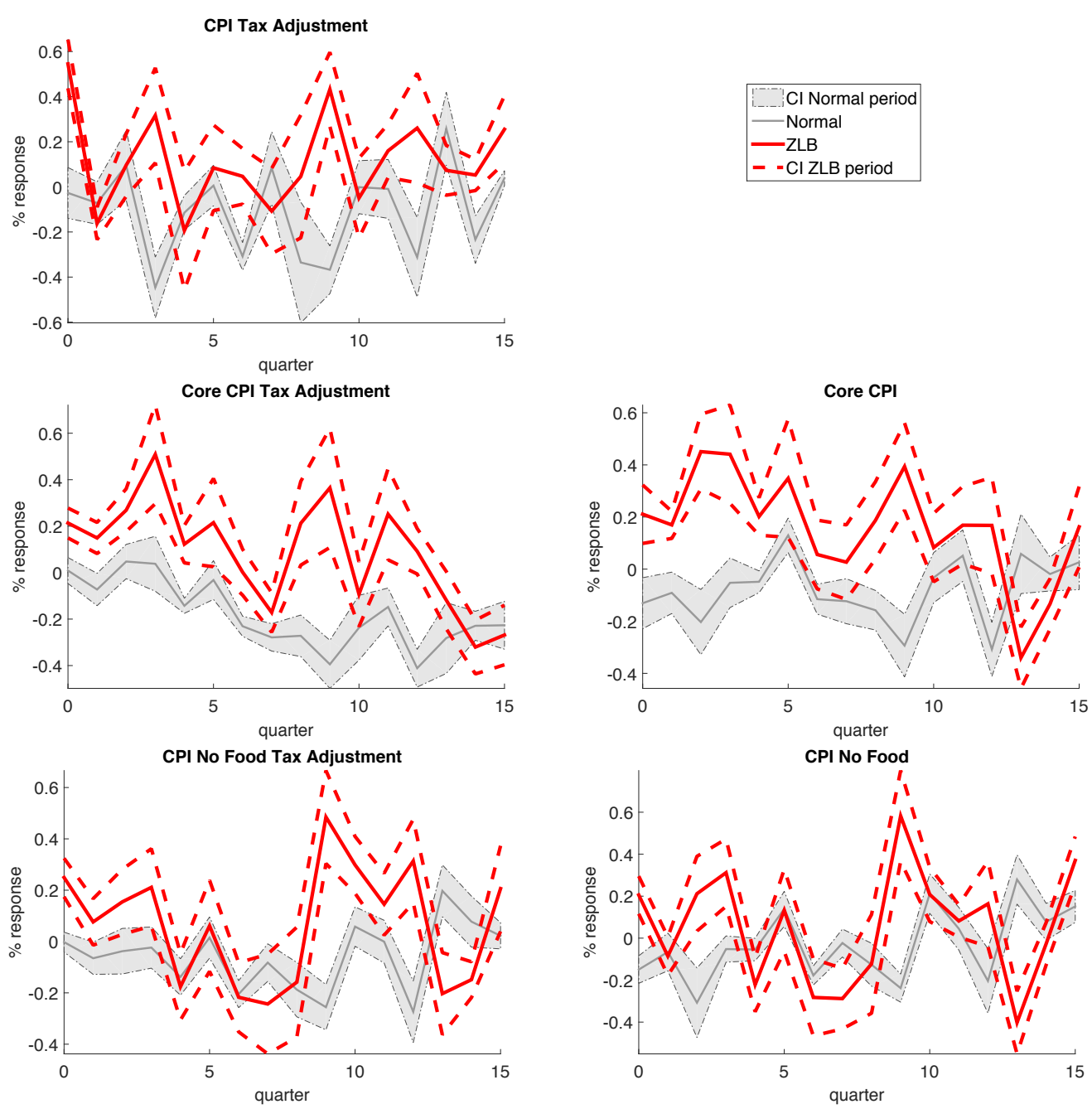

Notes: This figure plots the impulse responses of the inflation rate calculated from CPI, core CPI (excluding food and energy) and CPI no food (excluding fresh food), along with the measures of CPI inflation adjusted for consumption tax changes.

Figure A12: Cumulative Multipliers of Net Exports and Real Exchange Rate Multipliers
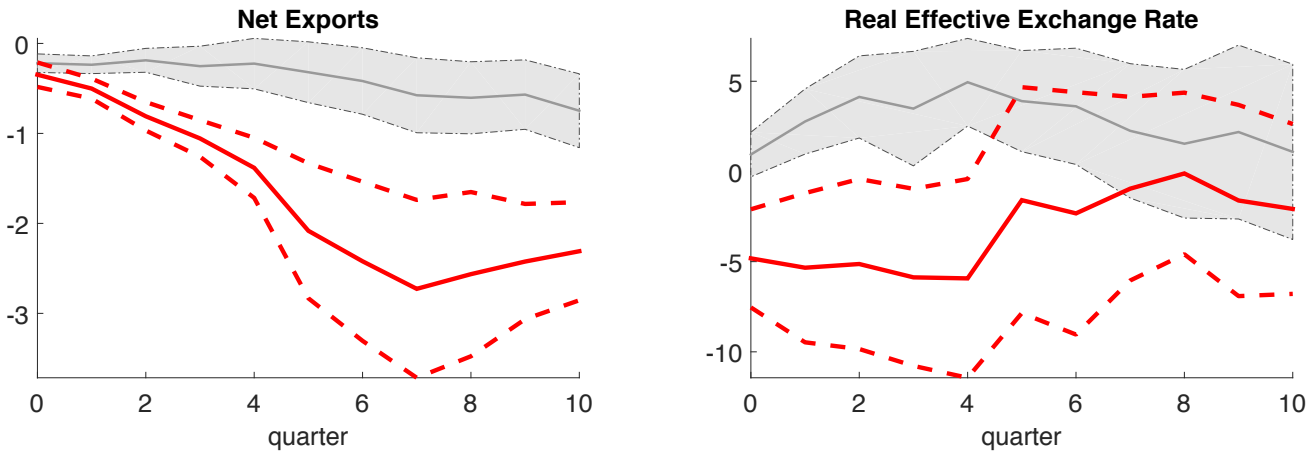

Notes: An increase in the real exchange rate is an appreciation. 
Figure A13: Components of Consumption and Investment Multipliers
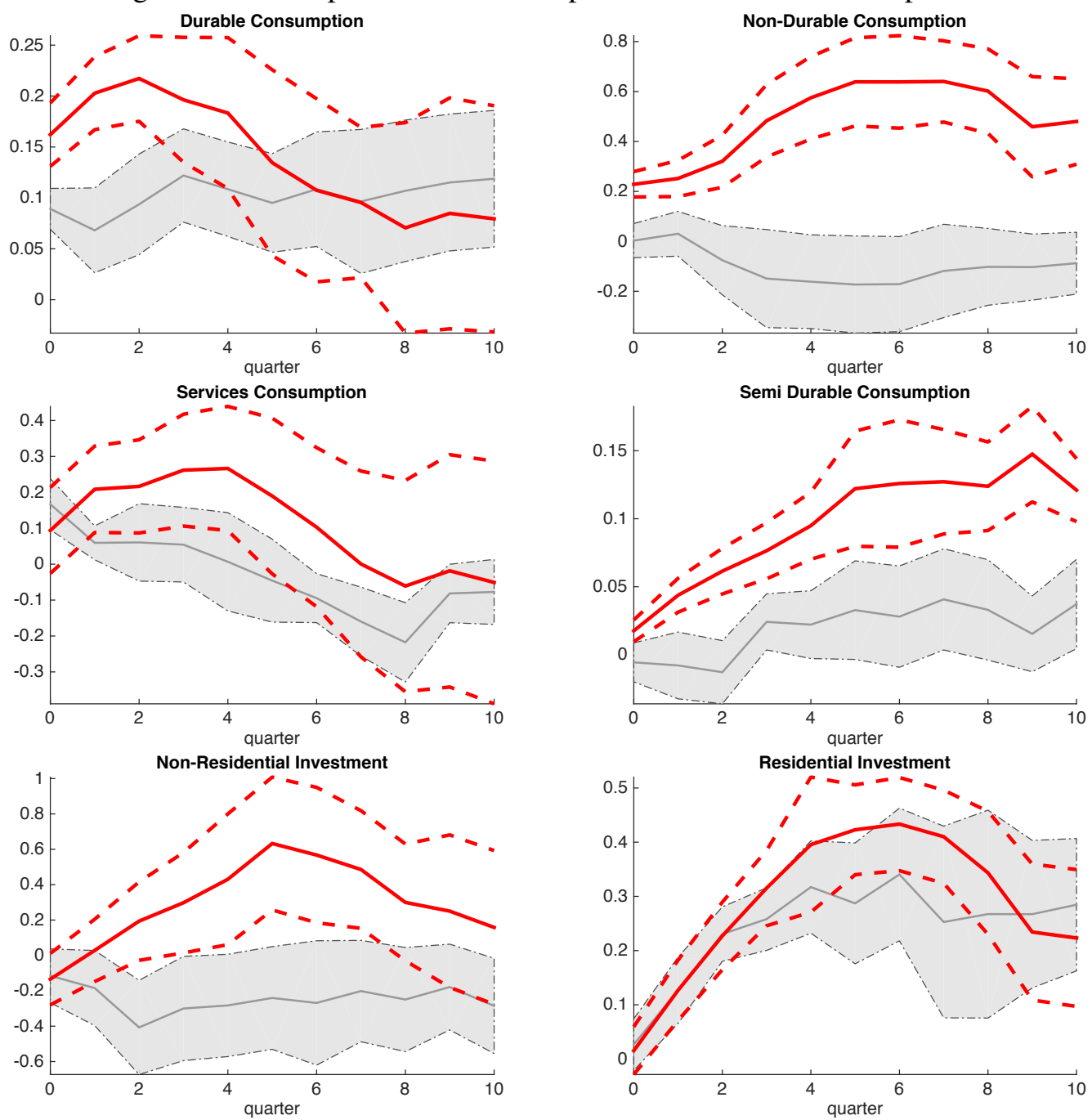

Notes: This figure plots the cumulative multipliers for the consumption of durables, non-durables, services, as well as residential and non-residential investment. The estimation specification is the same as consumption and investment in the baseline.
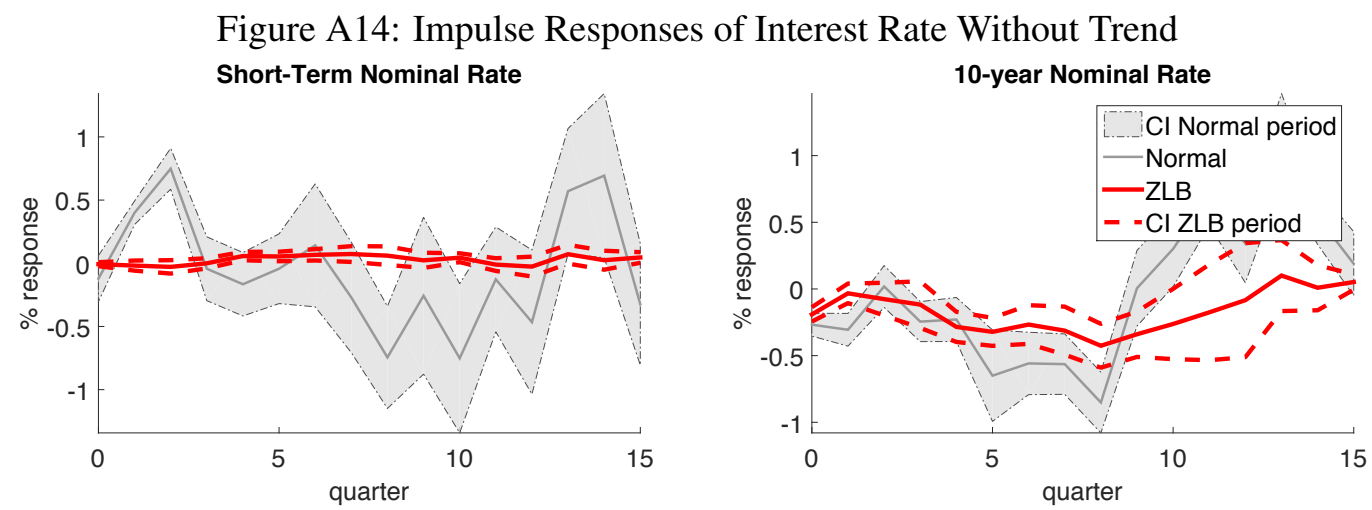

Notes: This figure plots the responses of the nominal interest rate when there is no trend in the specification. 